\title{
Activation of cryptic xylose metabolism by a transcriptional activator Znf1 boosts up xylitol production in the engineered Saccharomyces cerevisiae lacking xylose suppressor BUD21 gene
}

\author{
Pattanan Songdech' ${ }^{1}$ Rawitsara Intasit ${ }^{1}$, Yodying Yingchutrakul ${ }^{2}$, Chutikarn Butkinaree ${ }^{2}$,
} Khanok Ratanakhanokchai ${ }^{1,3}$ and Nitnipa Soontorngun ${ }^{1 *}$ (D)

\begin{abstract}
Background: Xylitol is a valuable pentose sugar alcohol, used in the food and pharmaceutical industries. Biotechnological xylitol production is currently attractive due to possible conversion from abundant and low-cost industrial wastes or agricultural lignocellulosic biomass. In this study, the transcription factor Znf1 was characterised as being responsible for the activation of cryptic xylose metabolism in a poor xylose-assimilating S. cerevisiae for xylitol production.

Results: The results suggest that the expression of several xylose-utilising enzyme genes, encoding xylose reductases for the reduction of xylose to xylitol was derepressed by xylose. Their expression and those of a pentose phosphate shunt and related pathways required for xylose utilisation were strongly activated by the transcription factor Znf1. Using an engineered S. cerevisiae strain overexpressing ZNF1 in the absence of the xylose suppressor bud21 $\triangle$, xylitol production was maximally by approximately $1200 \%$ to $12.14 \mathrm{~g} / \mathrm{L}$ of xylitol, corresponding to $0.23 \mathrm{~g} / \mathrm{g}$ xylose consumed, during 10\% (w/v) xylose fermentation. Proteomic analysis supported the role of Znf1 and Bud21 in modulating levels of proteins associated with carbon metabolism, xylose utilisation, ribosomal protein synthesis, and others. Increased tolerance to lignocellulosic inhibitors and improved cell dry weight were also observed in this engineered bud21 $1+$ pLJ529-ZNF1 strain. A similar xylitol yield was achieved using fungus-pretreated rice straw hydrolysate as an eco-friendly and low-cost substrate.
\end{abstract}

Conclusions: Thus, we identified the key modulators of pentose sugar metabolism, namely the transcription factor Znf1 and the suppressor Bud21, for enhanced xylose utilisation, providing a potential application of a generally recognised as safe yeast in supporting the sugar industry and the sustainable lignocellulose-based bioeconomy.

Keywords: Bioconversion, Metabolic engineering, Transcription factor Znf1, Xylose utilisation, Xylitol, Yeast

\footnotetext{
*Correspondence: nitnipa.soo@kmutt.ac.th

${ }^{1}$ Division of Biochemical Technology, School of Bioresources

and Technology, King Mongkut's University of Technology Thonburi, Bangkok 10150, Thailand

Full list of author information is available at the end of the article
}

\section{Background}

Xylitol has been identified as one of the top 12 valueadded compounds to be attained from biomass [1]. It is a natural sweetener used as a sugar substitute in the food and pharmaceutical industries. It offers advantageous original author(s) and the source, provide a link to the Creative Commons licence, and indicate if changes were made. The images or other third party material in this article are included in the article's Creative Commons licence, unless indicated otherwise in a credit line to the material. If material is not included in the article's Creative Commons licence and your intended use is not permitted by statutory regulation or exceeds the permitted use, you will need to obtain permission directly from the copyright holder. To view a copy of this licence, visit http://creativecommons.org/licenses/by/4.0/. The Creative Commons Public Domain Dedication waiver (http://creativeco mmons.org/publicdomain/zero/1.0/) applies to the data made available in this article, unless otherwise stated in a credit line to the data. 
properties as a low-calorie sweetener with insulin-independent metabolism and enables the control of calorie intake of consumers [2]. Furthermore, xylitol can be used in the biomedical industry as an intermediate for the synthesis of biodegradable polymers [3]. Owing to these properties, demand for xylitol by the food and pharmaceutical industries has increased. The worldwide market of xylitol is estimated to be more than 700 million tons per year, and its selling price is approximately 4-5 US dollars per kilogram, making it more expensive than other sugars [4]. Currently, xylitol is industrially produced through the chemical hydrolysis of xylan and xylose-hydrogenation reactions. Alternatively, the use of lignocellulose as a raw material has resulted in growing interest in the microbiological production of xylitol. This method is more environmentally friendly than the chemical method, which requires expensive equipment, extensive purification steps, and huge energy demand [5].

Several yeasts are naturally capable of consuming xylose through a xylose reductase/xylitol dehydrogenase $(\mathrm{XR} / \mathrm{XDH})$ pathway for the conversion of xylose into xylitol and subsequently to xylulose. Xylitol is a metabolic intermediate and by-product of this pathway, mainly resulting from the co-factor imbalance between the reaction catalysed by the $\mathrm{NAD}(\mathrm{P}) \mathrm{H}$-dependent xylose reductase with a preference for NADPH and the $\mathrm{NAD}^{+}$-dependent xylitol dehydrogenase [2]. For example, strains of native xylose-utilising yeast Pichia stipitis or Scheffersomyces stipitis (CBS 5773, 5774, 5775, 5776) produce xylitol at $0.05-0.19 \mathrm{~g} / \mathrm{g}$ xylose consumed using $30 \mathrm{~g} / \mathrm{L}$ xylose, $\mathrm{pH}$ 5.0, in anaerobic conversion experiments [6]. Hansenula polymorpha ATCC 34438 also produces xylitol at $12 \mathrm{~g} / \mathrm{L}$ or $0.61 \mathrm{~g} / \mathrm{g}$ xylose consumed, when using $20 \mathrm{~g} / \mathrm{L}$ xylose after $75 \mathrm{~h}$ of fermentation [7]. Kluyveromyces marxianus IMB5 produces xylitol at $1.3 \mathrm{~g} / \mathrm{L}$ or $0.25 \mathrm{~g} / \mathrm{g}$ from $20 \mathrm{~g} / \mathrm{L}$ of xylose after $48 \mathrm{~h}$ of fermentation [8]. Meyerozyma guilliermondii produces a high yield of $40.40 \mathrm{~g} / \mathrm{L}$ xylitol or $0.49 \mathrm{~g} / \mathrm{g}$ of consumed xylose from $100 \mathrm{~g} / \mathrm{L}$ xylose after 10 days of fermentation [9]. Naturally xylose-assimilating yeasts have been extensively studied during glucose-xylose co-fermentation for xylitol production. During co-fermentation, Debaryomyces hansenii and Candida guilliermondii produce xylitol from rapeseed straw detoxified hydrolysates after $144 \mathrm{~h}$ at $0.45 \mathrm{~g} / \mathrm{g}$ xylose consumed [10]. Kluyveromyces marxianus (CCA 510) produces xylitol at $6.76 \mathrm{~g} / \mathrm{L}$, after $96 \mathrm{~h}$ of cashew apple bagasse hydrolysate fermentation [11]. Candida guilliermondii also produces $32.7 \mathrm{~g} / \mathrm{L}$ of xylitol after $48 \mathrm{~h}$ of fermentation of a eucalyptus hemicellulosic hydrolysate [12]. Nevertheless, the yields of xylitol produced from xylose are still limited because xylose is also used for cell metabolism and energy maintenance; moreover, some yeast species are considered unsafe for use in the food industry such as $P$. stipites, and M. guilliermondii [13].

The yeast $S$. cerevisiae, a generally recognised as safe microorganism, is naturally incapable of efficient xylose metabolism. Currently, there are two major successfully implemented strategies for xylose utilisation by $\mathrm{S}$. cerevisiae via the oxidoreductase $(\mathrm{XR} / \mathrm{XDH})$ pathway and the xylose isomerase (XI) pathway. The oxidoreductase strategy uses a xylose reductase (XR) that reduces xylose to xylitol, preferably using NADPH over NADH as the cofactor, and a xylitol dehydrogenase (XDH) that uses only $\mathrm{NAD}^{+}$as the cofactor to convert xylitol to xylulose [14]. The XR/XDH pathway utilisation has a major bottleneck caused by the issue of cofactor imbalance between the NADPH-dependent XR- and the $\mathrm{NAD}^{+}$-dependent $\mathrm{XDH}$-reactions, causing the accumulation of xylitol and thus lowering ethanol production [15]. Secondly, the isomerase pathway, which is mainly found in bacteria, is a one-step reaction catalysed by XI. This enzyme directly converts xylose to xylulose without requiring cofactors $[16,17]$. However, XI activity is inhibited by xylitol formation by the unspecific endogenous NADPH-dependent aldose reductase (GRE3) gene product that converts xylose to xylitol [18]. Additionally, overexpression of genes involved in the non-oxidative pentose phosphate (PPP) shunt and deletion of the GRE3 gene improve xylose utilisation in strains expressing the xylose-utilising pathway [19].

The ability of some industrial yeasts to utilise xylose has been mapped to a putative xylitol dehydrogenase gene, $X D H 1$, which is not present in the laboratory $S$. cerevisiae S288C strain [20]. Xylitol dehydrogenase activity requires the endogenous XR genes GRE3 and YPR1 and the endogenous XKS1 gene to allow for xylose utilisation. Three putative XDH genes, i.e. SOR1, SOR2, and $X Y L 2$, can suppress the ability of $X D H 1$-expressing strains to utilise xylose, as shown by increased expression of enzymes with xylose reductase activity. This has emerged as a potential solution to increase xylitol yields from xylose [20, 21]. Additionally, overexpression of genes involved in the non-oxidative pentose phosphate (PPP) shunt and deletion of the GRE3 gene also improve xylose utilisation in strains expressing the xylose-utilising pathway [19]. Surprisingly, synthetic genomic array (SGA) identified genes whose modification affects xylose consumption, including BUD21, encoding a less wellcharacterised component of the small ribosomal subunit [22]. When these genes were individually deleted, xylose utilisation was improved in both S. cerevisiae S288C and CEN.PK strains [22]. Importantly, the BUD21 deletion strain, characterised in batch fermentation, was found to produce increased levels of xylitol $(1.35 \mathrm{~g} / \mathrm{L})$ and ethanol $(3.19 \mathrm{~g} / \mathrm{L})$ even in the absence of exogenous XI $(x y l A)$, 
demonstrating the suppressor ability of Bud21 in a laboratory S. cerevisiae strain utilising xylose as a sole carbon source [22]. This finding implies that S. cerevisiae may not require the addition of exogenous genes for xylose fermentation.

Previous studies on xylose fermentation by yeasts have revealed that some non-recombinant $S$. cerevisiae strains could slightly grow on xylose as a sole carbon source [23]. Despite the presence of all transporters and enzymes required for xylose utilisation in the genome of $S$. cerevisiae, their expression is just too low to ensure efficient xylose fermentation [24]; therefore, engineering exogenous genes of the xylose-utilising pathway has been the mainstream method to improve the xylose fermentation efficiency of S. cerevisiae. Despite several attempts to engineer xylose fermenting $S$. cerevisiae strains, the xylose metabolic pathway does not enable the yeast to rapidly and effectively utilise xylose. Several limitations still need to be overcome, including glucose repression, slow xylose transport, and cofactor imbalance in the xylose reductase/xylitol dehydrogenase pathway [25]. Alternatively, the approach that focuses on identifying and optimising the endogenous xylose-utilisation pathway in this yeast needs to be intensively investigated [22].

The role of the transcription factor Znf1 in alternative carbon source utilisation during the glucose-ethanol shift has been reported and is implicated in non-fermentable carbon source utilisation and stress responses [26, 27]. Recently, Znf1 was shown to be an activator of genes in glycolysis and alcoholic fermentation during high glucose fermentation [28]. Its overexpression leads to increased ethanol productivity and enhances tolerance to osmotic and weak-acid stresses [28]. A previous study reported that ZNF1 knockout strongly decreases xylose utilisation during the post-glucose effect, but its overexpression had no effect [29]. Additionally, in another study, the overexpression or deletion of the ZNF1 gene did not affect the fermentation ability of a xylose-fermenting strain engineered on the S. cerevisiae GS010 background [30]. Nevertheless, the role of Znf1 in xylose utilisation in native S. cerevisiae has never been fully explored. In this study, the aims were to investigate the transcriptional control of genes related to xylose metabolism, PPP, glycolysis, and the fermentative pathway governed by Znf1 and, secondly, to construct an S. cerevisiae ZNF1-overexpressing strain on different backgrounds with or without the Bud21 suppressor for co-fermentation of low glucosexylose or agricultural waste for potential xylitol production. The possibility of engineered $S$. cerevisiae strains to circumvent a major barrier that limits effective xylose utilisation from lignocellulosic biomass was investigated using gene and protein expression studies with batch fermentation.

\section{Results}

Rewiring xylose metabolism and related pathways during the glucose-xylose shift

In $S$. cerevisiae, utilisation of poor carbon sources such as xylose induces a starvation response and increases the expression of adaptive stress-response genes [31]. During growth in xylose, the expression of genes involved in xylose metabolism was significantly up-regulated when compared with growth under glucose conditions in the wild-type BY4742 strain [32] (Additional file 1: Table S1 and Fig. 1). The observed induction included multiple aldo-keto reductase genes for the conversion of xylose to xylitol, namely GRE3 (22.3-fold), YPR1 (2.4-fold), GCY1 (2.8-fold), YDL124W (3.1-fold), and YJR096W (2.0-fold), as well as xylitol dehydrogenase genes for the conversion of xylitol to xylulose, including XYL2 (3.0-fold), SOR1 (2.0-fold), and SOR2 (2.3-fold), and a xylulokinase gene XKS1 (2.9-fold) for the conversion of D-xylulose and ATP to xylulose 5-phosphate and ADP (Additional file 1: Table S1 and Fig. 1). Thus, in the absence of glucose, even for the native yeast $S$. cerevisiae, xylose could effectively induce the expression of endogenous genes required for the metabolism and utilisation of xylose as a sole carbon source. Interestingly, the expression of the small BUD21 gene, known to repress xylose utilisation, was also up-regulated (2.2-fold) during growth in xylose in the wild-type strain (Additional file 1: Table S1 and Fig. 1). In agreement, previous RNA-seq data has indicated that the S. cerevisiae wild-type Y133 strain shows significantly increased in mRNA levels of ZNF1 and BUD21 during anaerobic xylose growth [33], supporting their major role as a transcription factor and modulator of xylose utilisation, respectively.

Additionally, the transcriptional control of genes involved in gluconeogenesis, glycolysis, and the pentose phosphate pathway (PPP), was also investigated during growth in xylose, as these metabolic pathways are tightly interconnected with xylose utilisation. In the wild-type $S$. cerevisiae, the expression of gluconeogenic genes, namely HXK1 (25.6-fold), TDH1 (3.9-fold), ENO1 (2.2-fold), PYC1 (2.8-fold), and ADH2 (9.1-fold), was also up-regulated during the glucose-xylose shift (Additional file 1: Table S1 and Fig. 1). This suggested the ability of this strain to utilise a C5 carbon for the synthesis of glucose-6-phosphate, a key metabolic precursor providing the RNA backbone precursors ribose 5-phosphate and erythrose 4-phosphate for aromatic amino acid production important for cell proliferation and survival [34, 35]. In fact, gluconeogenesis is a key pathway for cells to drive the flux though acetyl-CoA, a key substrate in the tricarboxylic acid (TCA) cycle important for basic cellular functions such as energy supply as well as lipid and amino acid metabolism [36]. 
Table 1 Fermentation profiles of engineered S. cerevisiae strains during growth in YP media containing $0.05 \%$ glucose $(\mathrm{w} / \mathrm{V})$ mixed with $2 \%$ xylose or $10 \%$ xylose* $(\mathrm{w} / \mathrm{v})$ at day 8 or day $14^{*}$ of fermentation which provide maximal xylitol concentrations, respectively

\begin{tabular}{|c|c|c|c|c|c|c|}
\hline Parameter/Strains & Day & BY4742 + pRS316 & BY4742 + pLJ529-ZNF1 & $z n f 1 \Delta+p R S 316$ & bud21 $1+\mathrm{pRS} 316$ & bud21 $1 \Delta+$ pLJ529 - ZNF1 \\
\hline Initial DCW (g/L) & 0 & 0.23 & 0.23 & 0.23 & 0.23 & 0.23 \\
\hline Final DCW (g/L) & $\begin{array}{l}\text { Day } 8 \\
\text { Day } 14^{*}\end{array}$ & $\begin{array}{l}0.99 \pm 0.02 \\
1.30 \pm 0.01\end{array}$ & $\begin{array}{l}0.95 \pm 0.06 \\
1.16 \pm 0.02\end{array}$ & $\begin{array}{l}0.53 \pm 0.03 \\
0.88 \pm 0.04\end{array}$ & $\begin{array}{l}1.67 \pm 0.08 \\
1.47 \pm 0.03\end{array}$ & $\begin{array}{l}2.19 \pm 0.06 \\
3.14 \pm 0.03\end{array}$ \\
\hline $\begin{array}{l}\text { Biomass specific rates } \\
(\mathrm{g} / \mathrm{L} / \mathrm{h})\end{array}$ & $\begin{array}{l}\text { Day } 8 \\
\text { Day } 14^{*}\end{array}$ & $\begin{array}{l}0.005 \\
0.004\end{array}$ & $\begin{array}{l}0.005 \\
0.003\end{array}$ & $\begin{array}{l}0.003 \\
0.003\end{array}$ & $\begin{array}{l}0.009 \\
0.004\end{array}$ & $\begin{array}{l}0.011 \\
0.009\end{array}$ \\
\hline Xylose residues (g/L) & $\begin{array}{l}\text { Day } 8 \\
\text { Day } 14^{*}\end{array}$ & $\begin{array}{l}15.71 \pm 0.02 \\
57.13 \pm 0.53\end{array}$ & $\begin{array}{l}14.70 \pm 0.04 \\
49.90 \pm 0.21\end{array}$ & $\begin{array}{l}18.55 \pm 0.07 \\
76.81 \pm 2.33\end{array}$ & $\begin{array}{l}3.34 \pm 0.03 \\
41.05 \pm 1.10\end{array}$ & $\begin{array}{l}3.12 \pm 0.04 \\
34.29 \pm 2.51\end{array}$ \\
\hline Xylitol (g/L) & $\begin{array}{l}\text { Day } 8 \\
\text { Day } 14^{*}\end{array}$ & $\begin{array}{l}0.29 \pm 0.02 \\
0.94 \pm 0.05\end{array}$ & $\begin{array}{l}0.48 \pm 0.04 \\
1.0 \pm 0.04\end{array}$ & $\begin{array}{l}0.27 \pm 0.00 \\
0.50 \pm 0.01\end{array}$ & $\begin{array}{l}0.63 \pm 0.04 \\
4.06 \pm 0.06\end{array}$ & $\begin{array}{l}1.26 \pm 0.04 \\
12.14 \pm 0.8\end{array}$ \\
\hline $\begin{array}{l}\text { Xylose consumption } \\
(\mathrm{g} / \mathrm{L} / \mathrm{h})\end{array}$ & $\begin{array}{l}\text { Day } 8 \\
\text { Day } 14^{*}\end{array}$ & $\begin{array}{l}0.02 \\
0.09\end{array}$ & $\begin{array}{l}0.02 \\
0.11\end{array}$ & $\begin{array}{l}0.005 \\
0.04\end{array}$ & $\begin{array}{l}0.08 \\
0.14\end{array}$ & $\begin{array}{l}0.09 \\
0.16\end{array}$ \\
\hline $\begin{array}{l}\text { Xylose consumption } \\
\text { rate (g/g CDW/h) }\end{array}$ & $\begin{array}{l}\text { Day } 8 \\
\text { Day } 14^{*}\end{array}$ & $\begin{array}{l}0.02 \\
0.07\end{array}$ & $\begin{array}{l}0.03 \\
0.13\end{array}$ & $\begin{array}{l}0.01 \\
0.05\end{array}$ & $\begin{array}{l}0.05 \\
0.09\end{array}$ & $\begin{array}{l}0.04 \\
0.05\end{array}$ \\
\hline $\begin{array}{l}\text { Xylitol yield }(\mathrm{g} / \mathrm{g}) \text { of } \\
\text { consumed xylose }\end{array}$ & $\begin{array}{l}\text { Day } 8 \\
\text { Day } 14^{*}\end{array}$ & $\begin{array}{l}0.08 \\
0.03\end{array}$ & $\begin{array}{l}0.10 \\
0.03\end{array}$ & $\begin{array}{l}0.14 \\
0.05\end{array}$ & $\begin{array}{l}0.04 \\
0.09\end{array}$ & $\begin{array}{l}0.08 \\
0.23\end{array}$ \\
\hline $\begin{array}{l}\text { Percentage change } \\
\text { in CDW improve- } \\
\text { ment }\end{array}$ & $\begin{array}{l}\text { Day } 8 \\
\text { Day } 14^{*}\end{array}$ & $\begin{array}{l}- \\
-\end{array}$ & $\begin{array}{l}-3.67 \\
-10.78\end{array}$ & $\begin{array}{l}-46.17 \\
-32.31\end{array}$ & $\begin{array}{l}+68.48 \\
+13.00\end{array}$ & $\begin{array}{l}+120.81 \\
+114.90\end{array}$ \\
\hline $\begin{array}{l}\text { Maximum Percent- } \\
\text { age change in xylitol } \\
\text { yield }\end{array}$ & $\begin{array}{l}\text { Day } 8 \\
\text { Day } 14^{*}\end{array}$ & - & $\begin{array}{l}+68.42 \\
+6.95\end{array}$ & $\begin{array}{l}-5.26 \\
-46.81\end{array}$ & $\begin{array}{l}+119.30 \\
+334.22\end{array}$ & $\begin{array}{l}+340.35 \\
+1198.90\end{array}$ \\
\hline
\end{tabular}

Results of at least two independent experiments performed in triplicates were shown

On the other hand, the expression of PGI1, TPI1 and GPM1, components of the glycolysis pathway, as well as $A D H 1$ involved in alcohol fermentation, was downregulated by approximately twofold during growth on xylose as the sole carbon source; in glucose-grown cells, expression of these genes was de-repressed by approximately twofold (Additional file 1: Table S1 and Fig. 1), suggesting the rewiring of carbon metabolism. The expression of genes involved in glycerol biosynthesis (GPD1/2 and GPP1/2) remained unchanged, while the expression of TCA cycle genes including COX1 (6.4-fold), CYC3 (3.1-fold), and GDH2 (7.0-fold) was strongly up-regulated during xylose induction in the wild-type strain (Additional file 1: Table S1 and Fig. 1). This suggests that glycolysis flux is low and the metabolism of cells appears to be shifted from fermentation to respiration mode, as also found during glucose depletion [37]. During the transition from glucose to xylose, many genes in the PPP, such as ZWF1 (3.1-fold), RKI1 (5.9-fold), GND1 (5.5-fold), TAL1 (2.2-fold), and TKL2 (2.2-fold), were also up-regulated while the expression of SOL3/4 and RPE1 was down-regulated (2.0-fold) in the wild-type $S$. cerevisiae following xylose induction (Additional file 1: Table S1 and Fig. 1). Previously, overexpression of $Z W F 1$ was shown to drive metabolic flux from glucose into the PPP to increase xylose utilisation during simultaneous xylose and glucose fermentation [38]. Moreover, the oxidative PPP and gluconeogenesis are enhanced during anaerobic xylose growth, possibly driven by increased demand for the cofactor NADPH [39].

\section{The transcription factor Znf1 actively up-regulated} the expression of genes involved in xylose utilisation

Since the transcription factor Znf1 is activated during glucose de-repression and is responsible for the up-regulated expression of several genes required for utilisation of alternative carbon sources [26], its role in xylose metabolism was addressed. First, in the wild-type glucose grown cells, Znf1 was shown to activate some genes in glycolysis and the alcohol dehydrogenase $A D H 1$ gene, but no significant alteration of PGI1, FBA1, and ENO1 expression was observed (Additional file 1: Table S1 and Fig. 1). During the glucose-xylose shift, expression of xylose utilisation genes was dramatically up-regulated in the wild-type strain, compared to the $z n f 1 \Delta$ strain S. cerevisiae BY4742, including xylose reductase genes such as GRE3 (25.0-fold), GCY1 (3.3-fold), YDL124W (3.3-fold), and YJR096W (2.5-fold), xylitol dehydrogenase genes such as XYL2 (3.1-fold), SOR1 (2.0-fold), and SOR2 (2.0fold), as well as the xylose suppressor gene BUD21 (2.0fold) (Additional file 1: Table S1 and Fig. 1). These results are consistent with previous findings that the GRE3 and SOR1 genes of S. cerevisiae are capable of providing xylose reductase and xylitol dehydrogenase functions, thereby permitting cell growth on xylose as a sole carbon 


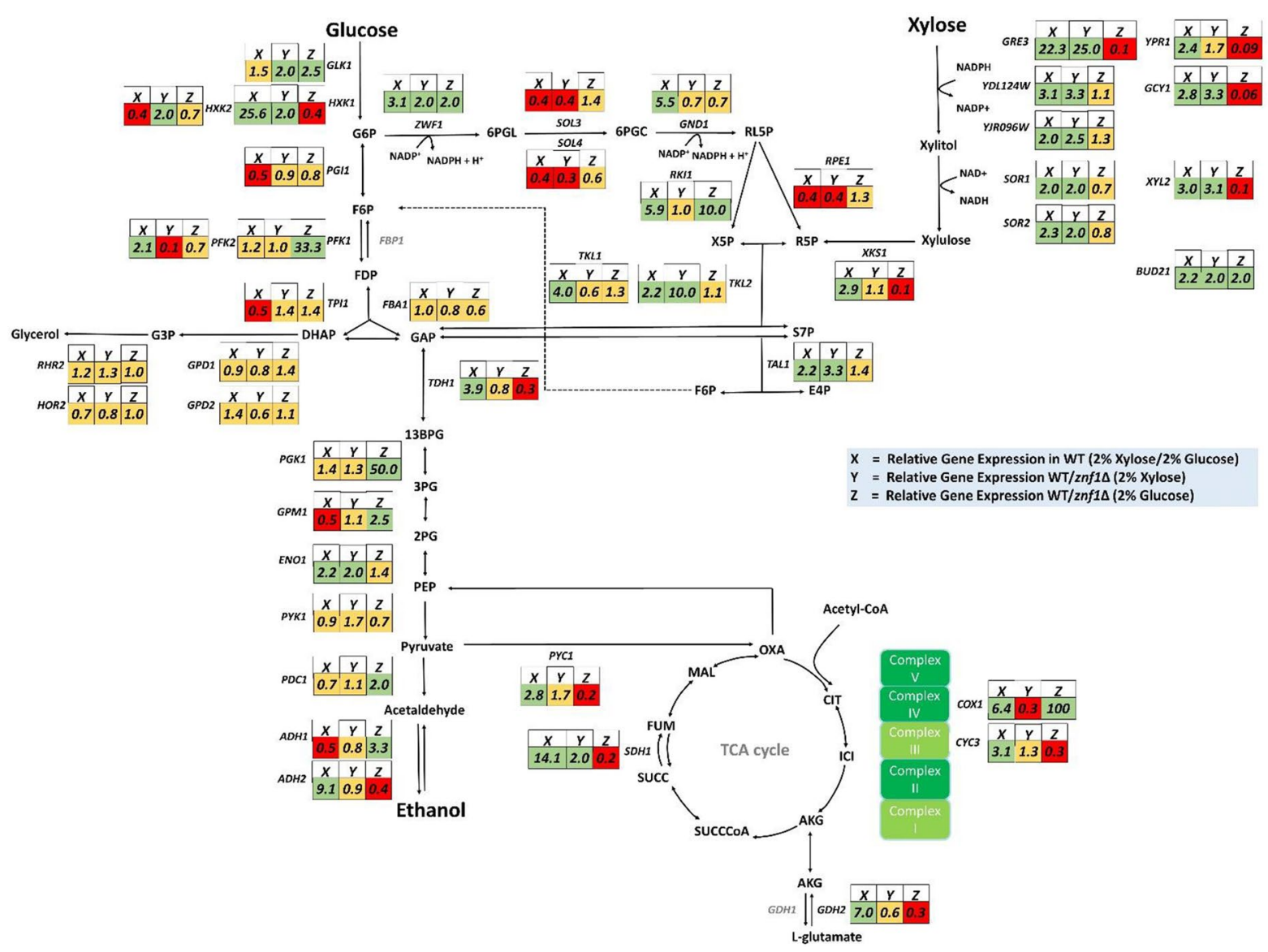

Fig. 1 Expression levels of Znf1 target genes during glucose-xylose shift. Relative expression levels of genes involved in xylose metabolism, pentose phosphate pathway, glycolysis, gluconeogenesis, glycerol metabolism and TCA cycle were examined using RT-qPCR. Changes in the levels of mRNAs were indicated as following: $2 \%$ xylose shift in the wild-type strain (the X rectangle box), in the wild-type strain relative to the znfi $\triangle$ strain during the $2 \%$ xylose shift (the $Y$ rectangle box) and, in the wild-type strain relative to the $z n f 1 \triangle$ strain during growth in $2 \%$ glucose (the $Z$ rectangle box). Green, red or yellow color box indicated genes whose expression was either activated/induced, repressed or unaltered by xylose or the transcription factor Znf1, respectively. The relative expression levels were obtained via the comparative $C_{t}$ method for quantification of the $\Delta \Delta C_{\mathrm{t}}$ values. Altered expression more than 2 -folds was considered significant. The arrowheads in the figure represent the direction of enzymatic reactions. Abbreviations: ADH1, alcohol dehydrogenase I; $A D H 2$, alcohol dehydrogenase II; BUD21, component of small ribosomal subunit/ xylose suppressor; COX1, cytochrome c oxidase; CYC3, cytochrome c heme lyase; ENO1, enolase; FBA1, fructose 1,6-bisphosphate aldolase; GCY1, glycerol dehydrogenase; GDH2, glutamate dehydrogenase; GLK1, glucokinase; GND1, 6-phosphogluconate dehydrogenase; GPD1, glycerol-3-P dehydrogenase; GPD2, glycerol-3-P dehydrogenase; GPM1, phosphoglycerate mutase; GPP1, glycerol-3-P phosphatase; GPP2, glycerol-3-P phosphatase; GRE3, aldose reductase; HXK1, hexokinase isoenzyme 1; HXK2, hexokinase isoenzyme II; PFK1, phosphofructokinase 1; PFK2, phosphofructokinase II; PGI1, phosphoglucose isomerase; PGK1, 3-phosphoglycerate kinase; PDC1, pyruvate decarboxylase; PYC1, pyruvate carboxylase; PYK1, pyruvate kinase; RKI1, ribose-5-phosphate ketol-isomerase; RPE1, ribulose-5-phosphate 3-epimerase; SDH1, succinate dehydrogenase; SOL3, 6-phosphogluconolactonase; SOL4, 6-phosphogluconolactonase; SOR1, sorbitol dehydrogenase; SOR2, sorbitol dehydrogenase; TAL1, transaldolase; TDH1, glyceraldehyde-3-phosphate dehydrogenase; TKL1, transketolase; TKL2, transketolase; TPI1, triose phosphate isomerase; XKS1, xylulokinase; XYL2, xylitol dehydrogenase; YDL124W, NADPH-dependent alpha-keto amide reductase; YJR096W, xylose and arabinose reductase; YPR1, NADPH-dependent aldo-keto reductase; ZWF1, glucose-6-phosphate dehydrogenase. Compounds, AKG, a-ketoglutarate; 13BPG, 1,3-bisphosphoglycerate; CIT, citrate; DHAP, dihydroxyacetone phosphate; E4P, erythrose 4-phosphate; FDP, fructose-1,6-diphosphate; F6G, fructose-6-phosphate; FUM, fumarate; GAP, glyceraldehyde-3-phosphate; G6P, glucose-6-phosphate; G3P, glyceraldehyde-3-phosphate; ICl, isocitrate; PEP, phosphoenolpyruvate; 3PG, 3-phosphoglycerate; 6PGC, 6-phosphogluconate; 6PGL, 6-phospho-gluconolactonase; MAL, malate; OXA, oxaloacetate; R5P, ribose 5-phosphate; RL5P, ribulose 5-phosphate; S7P; sedoheptulose 7-phosphate; SUCCOA, succinyl COA; SUCC, succinate; X5P, xylulose 5-phosphate 
source [40]. Overall, in addition to non-fermentable carbon utilisation, gene expression analysis indicated that Znf1 is a key transcription regulator of xylose metabolism in S. cerevisiae.

In $2 \%$ xylose, the expression of some PPP genes was down-regulated in the wild-type strain by 2 to threefold when compared to the $z n f 1 \Delta$ strain, such as SOL4, $S O L 3$, and RPE1, suggesting a repressor role of Znf1 to block unnecessary expression of genes in the oxidative PPP branch. In contrast, ZNF1 dramatically activated the expression of TKL2 (10.0-fold), TAL1 (3.3-fold), and ZWF1 (2.0-fold) as compared to ZNF1 deletion strain (Additional file 1: Table S1 and Fig. 1), suggesting an activator role to promote the metabolism of pentose sugars such as xylose. These genes are important for generating key metabolites that are the main building blocks for the biosynthesis of nucleic acids, and aromatic amino acids, NADPH generation, and oxidative stress responses [41, 42]. Increased expression of TKL2, TAL1, and ENO1 by Znf1 during xylose utilisation may lead to a superior xylose-utilisation capability in the yeast strain. Recently, highly activated transketolase and transaldolase activity and their complex interactions in the non-oxidative PPP branch were found to be critical for serial sugar transformation to drive metabolic flow into glycolysis, which increases ethanol production [43]. Interestingly, in xylose, Znf1 mediated the activation of genes involved in lower glycolysis, which are responsible for driving the flux from phosphoenolpyruvate [44] to pyruvate and eventually to oxaloacetate (Additional file 1: Table S1 and Fig. 1). Upregulated expression of the $S D H 1$ gene of the TCA cycle (2.0-fold) (Additional file 1: Table S1 and Fig. 1), suggesting the rewiring of gene expression required for oxidative metabolism. These results indicate Znfl's control of metabolic flux toward the TCA cycle instead of ethanol formation, which is more beneficial to yeast cells during growth on a poor carbon source. Enhanced expression of genes involved in glycolysis was found in the xylosefermenting recombinant strain during the exponential growth phase of mixed sugar fermentation.

\section{Overexpression of ZNF1 increased xylose transport and metabolism}

A ZNF1-overexpressing strain (ZNF1-OE) was constructed using the CRISPR/Cas9 gene editing technique and its expression was increased 6.8-fold when compared to the wild-type strain BY4742. Gene expression of xylose reductases, targets of $\mathrm{Znf1}$, was also strongly up-regulated in this engineered strain when compared to the wild-type strain, including GCY1 (16.1-fold), GRE3 (20.4-fold), YDL124W (5.1-fold), and YJR096W (14.6-fold) (Fig. 2A). Likewise, expression of xylitol dehydrogenase genes, including XYL2 (19.2-fold), SOR1 (16.7-fold), SOR2 (4.9-fold) and also BUD21 (2.1-fold) (Fig. 2A), as well as genes involved in the upper glycolysis pathway such as $H X K 1$ (5.8-fold), and HXK2 (2.6fold), lower glycolysis genes GPM1 (2.7-fold), ENO1 (3.1-fold), and PYK1 (3.4-fold), the fermentation gene PDC1 (2.3-fold) (Fig. 2B) and PPP genes including ZWF1 (4.3-fold), GND1 (13.0-fold), and TAL1 (2.9-fold) (Fig. 2C) were highly increased in the ZNF1-overexpressing strain compared with the wild-type strain during growth in xylose. The xylose transporter is also known as a major bottleneck in xylitol production due to the lack of a specific pentose transporter in S. cerevisiae. Pentose sugars enter the cell with low affinity via glucose transporters of the Hxt family. Under low glucose conditions, xylose transport has been shown to be mediated through high-affinity glucose transporters. In the ZNF1-overexpressing strain, expression of $H X T 4$ (18.5-fold), HXT7 (55.5-fold), and GAL2 (64.5-fold) were increased in xylose (Fig. 2C), suggesting their important role as xylose-transporting proteins.

The overview of Znf1-mediated xylose utilisation and its target genes was summarised (Fig. 2D). Like glucose, xylose also enters yeast cells via hexose transporters whose expression is strongly induced and dependent on Znf1. Then, xylose is converted to xylitol via several xylose reductases whose expression is also under the control of the transcription factor Znf1. Xylitol is subsequently converted to xylulose via many xylitol

\footnotetext{
Fig. 2 Expression levels of genes involved in xylose metabolism in the ZNF1 overexpressing strain (ZNF1-OE) during the growth in 2\% xylose and 0.05\% glucose mix. A Relative expression levels of xylose metabolic genes (GCY1, GRE3, YDL 124W, YPR1, XYL2, SOR1, SOR2 and BUD21 genes) B glycolytic and alcoholic fermentative genes (HXK1, HXK2, GPM1, ENO1, PYK1, PDC1, and ADH1 genes) C hexose transporter and PPP genes (HXT4, HXT7, GAL2, ZWF1, GND1, and TAL1 genes) in ZNF1-OE strain compared to the wild type strain during the growth in $2 \%$ xylose and $0.05 \%$ glucose mix. The relative expression levels were obtained via the comparative $C_{t}$ method for quantification of the $\Delta \Delta C_{t}$ values. Altered expression levels more than 2-folds were considered significant. The average values were calculated from at least two independent experiments performed in three replicates. D Metabolic engineering strategy via overexpression of ZNF1 transcription factor gene to activate its target genes linked to xylose metabolism and deletion of xylose suppressor BUD21 in S. cerevisiae. The green arrow indicated induction of genes expressed by fold-changes which is compared to the wild-type BY4742 strain
} 


\section{A}

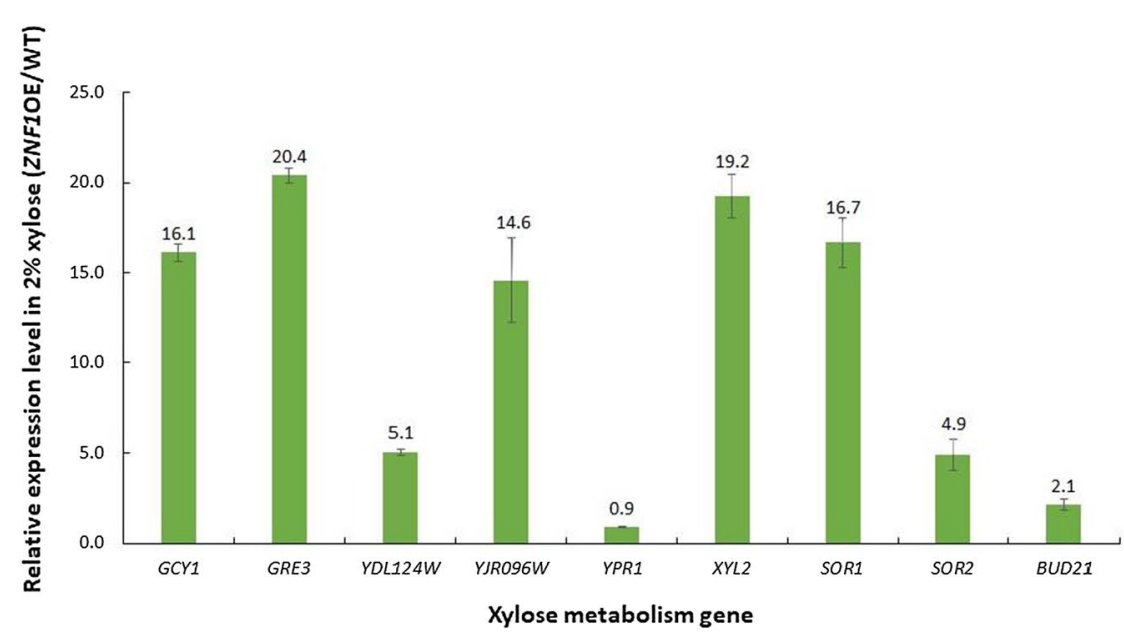

B

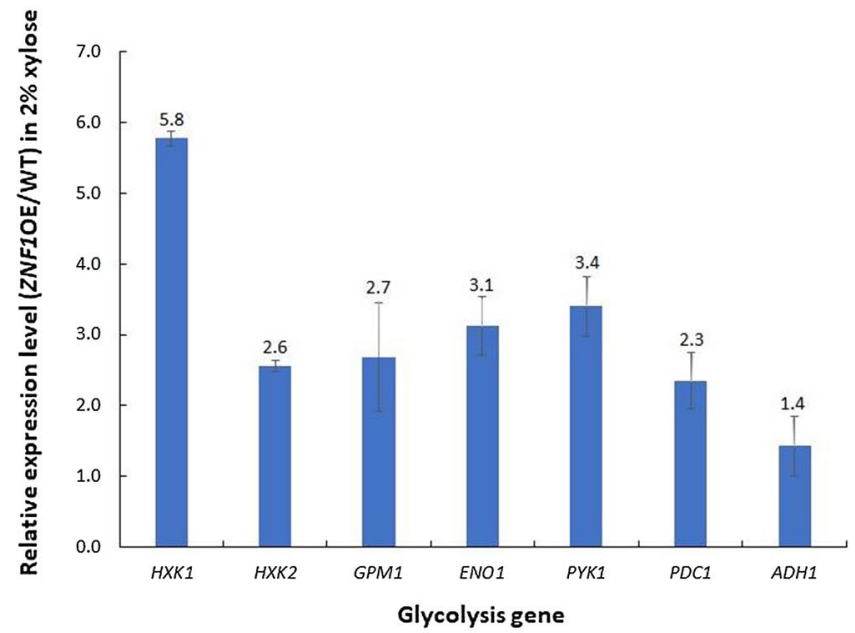

C

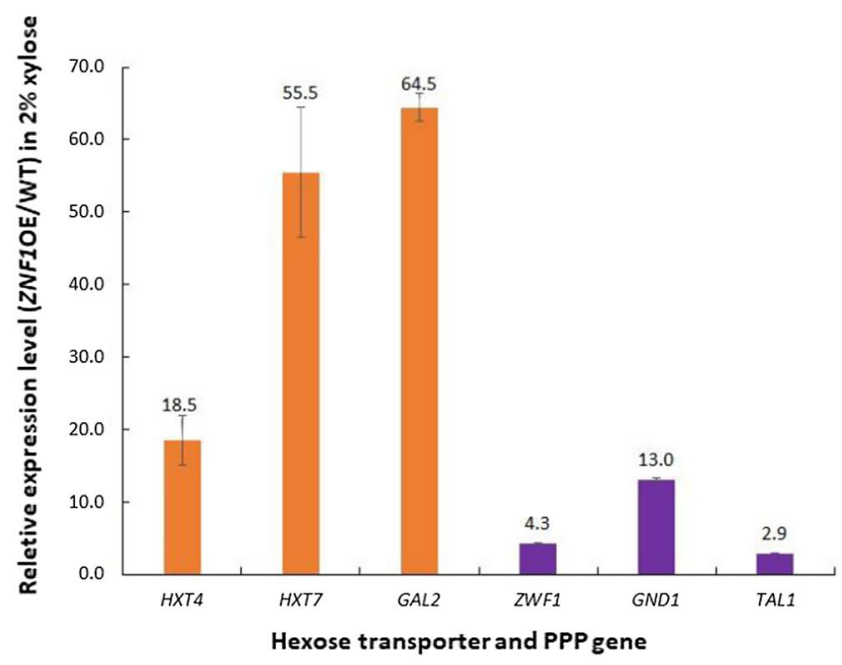




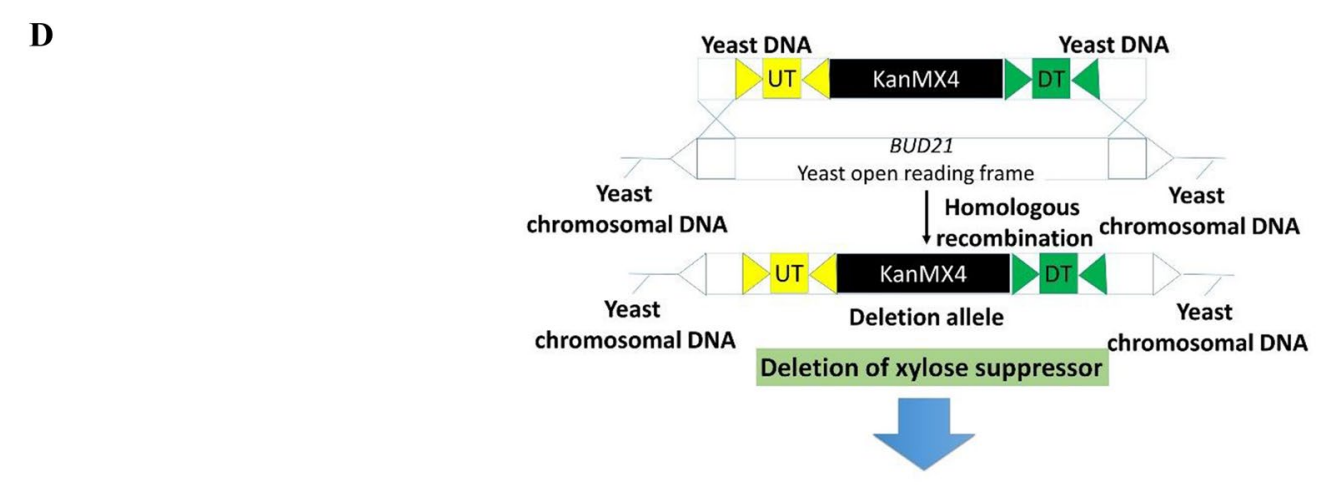

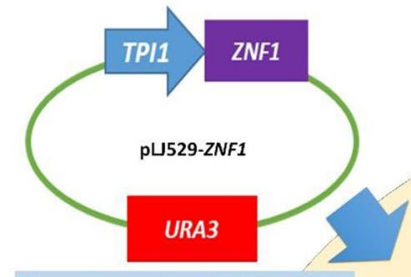

Overexpression Znf1 protein
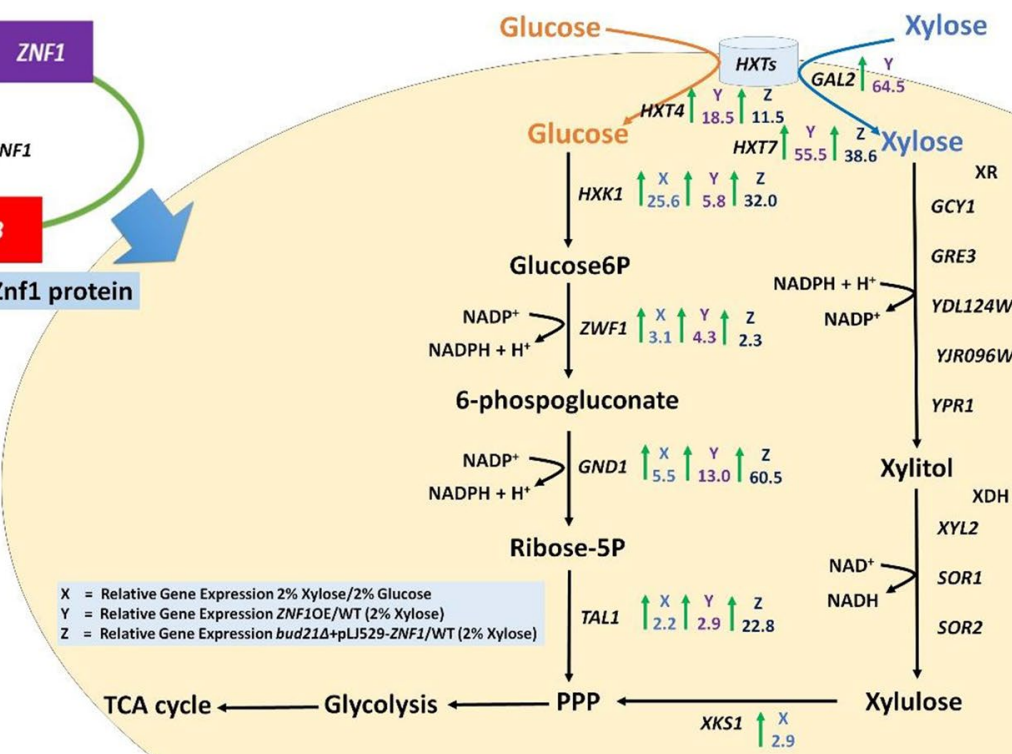$$
\text { i } z
$$

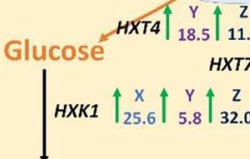

Glucose6P

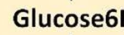

$\mathrm{PHH}+\mathrm{H}^{+}$

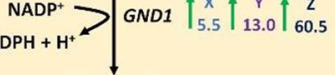

Ribose-5P

TALI $\uparrow_{2.2}^{X} \uparrow_{2.9}^{y} \uparrow_{22.8}^{z}$

$\mathrm{XKS1} \uparrow_{2.9}^{\mathrm{x}}$

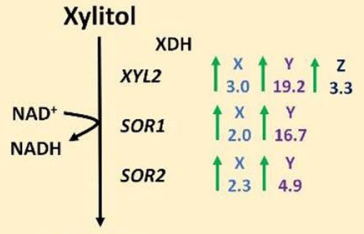

Xylulose

Fig. 2 continued

dehydrogenases, which all are targets of Znf1. Then, it is converted to xylulose 5-phosphate and ADP by xylulokinase, whose expression is not dependent on Znf1, prior to entering the PPP pathway. As shown in the present study, xylose induced the expression of key PPP genes, namely TAL1, GND1, and ZWF1 for the formation of the cofactor NADPH and glucose-6-phosphate. The expression of these genes was also positively regulated by Znf1, except for GND1. Since Znf1 chiefly modulates xylose metabolism, overexpression of ZNF1 was speculated to improve xylose utilisation and thus the production of xylose-derived metabolites, including xylitol. To further improve xylose fermentation, deletion of the xylose suppressor BUD21, known to increase xylose utilisation [22] and positively regulated by Znf1, was carried out to construct the bud21 + pLJ529ZNF1 strain. During xylose induction, the expression of genes encoding hexose transporters (HXT4, 11.5-fold; HXT7, 38.6-fold), xylose reductase (GCY1, 14.7-fold; GRE3, 17.2-fold; YDL124W, 8.2-fold), xylitol dehydrogenase (XYL2, 3.3-fold), and PPP components (TAL1, 22.8-fold; GND1, 60.5-fold; ZWF1, 2.3-fold) was dramatically increased in the bud21 + pLJ529-ZNF1 strain when compared to the wild-type strain (Fig. 2D).

\section{ZNF1 overexpression and BUD21 deletion increased} growth and xylose utilisation in S. cerevisiae

Different approaches have been used to enhance xylose transport, including co-fermentation of xylose with other carbon sources [45]. In this study, the 


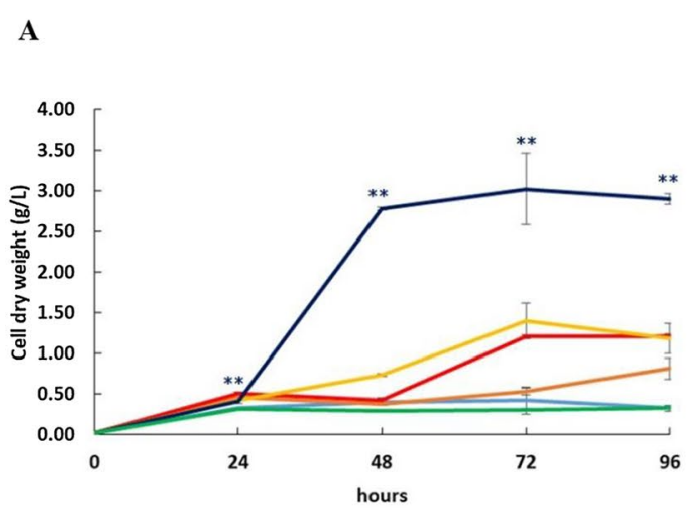

B
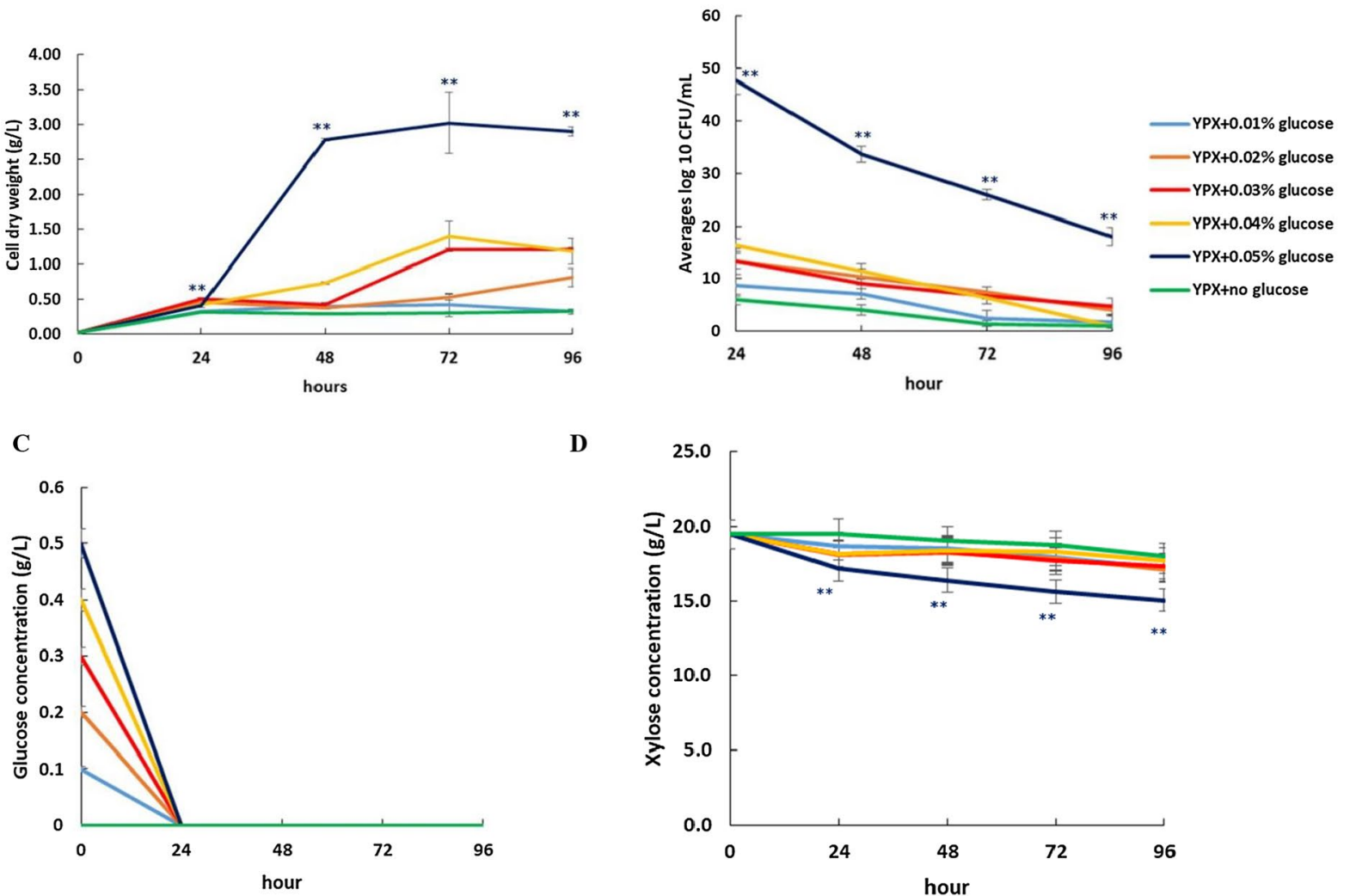

D

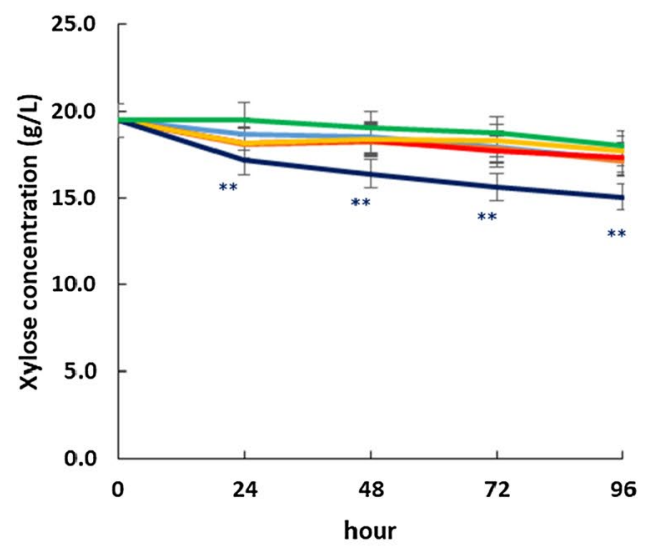

$\mathbf{E}$

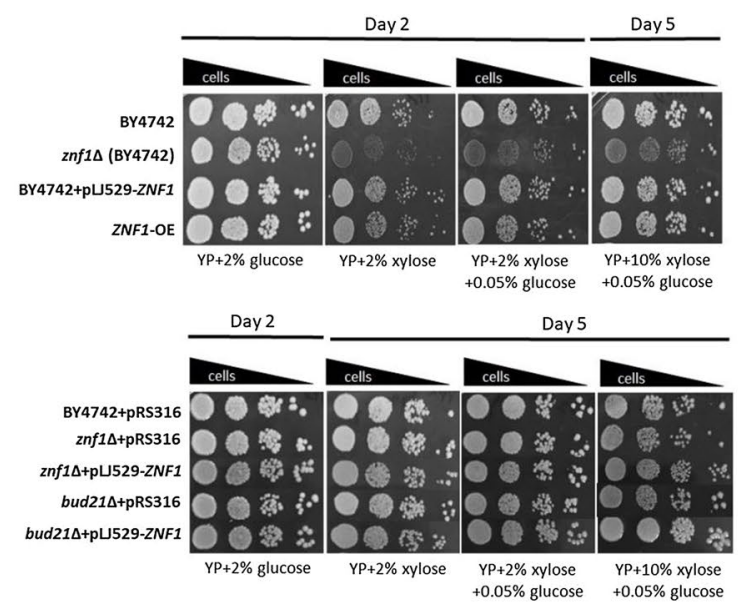

Fig. 3 Effect of low glucose-xylose mix on induction of xylose utilization in different S. cerevisiae strains. The ZNF1-OE strain overexpressing ZNF1 gene was investigated during culture in YPX containing $2 \%$ xylose $(\mathrm{W} / \mathrm{V})$ and low glucose at concentration of $0.05 \%, 0.04 \%, 0.03 \%, 0.02 \%$, $0.01 \%(\mathrm{w} / \mathrm{v})$ or without glucose expressed in term of cell dry weight $(\mathrm{g} / \mathrm{L})(\mathbf{A})$, Cell survival was analyzed using CFU/ml method (B), Glucose concentration $(\mathrm{g} / \mathrm{L})(\mathbf{C})$, Xylose concentration $(\mathrm{g} / \mathrm{L})(\mathbf{D})$, Phenotypic analysis on increased concentration of xylose (E). The wild-type BY4742, the znf1 $\triangle$, the bud21 $\triangle$, the rescued strain (Znf1 $\triangle+$ pLJ529-ZNF1) the overexpression ZNF1 (BY4742 + pLJ529-ZNF1 and ZNF1-OE), and the engineered bud21 $\triangle+$ pLJ529-ZNF1 of S. cerevisiae strains were observed on YPX agar plates contained $0.05 \%$ glucose mixed with different concentration of xylose at 2 or $10 \%(\mathrm{w} / \mathrm{v})$. Ten-fold serial dilutions of cells were spotted on plates and incubated at $30^{\circ} \mathrm{C}$ for $2-5$ days. Error bars indicated standard deviations calculated from at least two independent experiments performed in triplicate. Significance differences were determined by one-way ANOVA with Tukey HSD method (*, $\left.p<0.05 ;{ }^{* *}, p<0.01\right)$ 
ZNF1-overexpressing strain was tested for increased xylose utilisation in at mixed concentrations of low glucose and $2 \%(\mathrm{w} / \mathrm{v})$ xylose substrate. Interestingly, glucose at $0.05 \%(\mathrm{w} / \mathrm{v})$ was the best concentration for growth when compared with the other glucose concentrations tested (Fig. 3A). At lower glucose concentrations of $0.01-0.04 \%(\mathrm{w} / \mathrm{v})$, the final cell dry weights were increased by $2-260 \%$ after $48 \mathrm{~h}$ of fermentation with extended log phases of growth (Fig. 3A). The duration of the lag phase was significantly shorter using $0.05 \%(\mathrm{w} / \mathrm{v})$ glucose, and the highest cell dry weight was obtained at approximately $3.0 \mathrm{~g} / \mathrm{L}$, i.e. $778.21 \%$ increase (Fig. 3A). On the other hand, under no glucose conditions, the lag phase time was extended to $96 \mathrm{~h}$ or more with no significant increase in cell biomass observed (Fig. 3A). Furthermore, colony-forming unit (CFU) assays were conducted to examine cell survival, which may not have obviously been observed by the measurement of optical density. At $24 \mathrm{~h}$ of incubation under $2 \%$ xylose mixed with $0-0.05 \%$ glucose, the ZNF1OE strain showed dramatically increased cell colonyforming units $(\mathrm{CFU} / \mathrm{mL})$ at $47.67 \times 10^{7}$ as compared to growth without glucose $\left(\mathrm{CFU} / \mathrm{mL}\right.$ of $\left.6.00 \times 10^{7}\right)$, or $0.04 \%$ glucose $\left(\mathrm{CFU} / \mathrm{mL}\right.$ of $16.33 \times 10^{7}$ ) (Fig. $3 \mathrm{~B}$ ). Moreover, glucose consumption was completed within $24 \mathrm{~h}$ under the low percentage glucose concentrations tested, while the ZNF1-OE strain quickly consumed xylose under $2 \%$ xylose $+0.05 \%$ glucose (Fig. $3 \mathrm{C}$ ). Also, the xylose was consumed relatively quickly during the first $24 \mathrm{~h}$ and slightly decreased thereafter (Fig. 3D). Overall, these results demonstrate the effect of co-substrate utilisation between low glucose and xylose in the activation of xylose consumption.

Spot assays in agar YP plates containing $2 \%$ or $10 \%$ $(\mathrm{w} / \mathrm{v})$ xylose mixed with $0.05 \%(\mathrm{w} / \mathrm{v})$ glucose were also conducted to confirm the involvement of $\mathrm{Znf1}$ and Bud21 in xylose utilisation and osmotic stress tolerance (Fig. 3E). Growth of the $z n f 1 \Delta$ strain under a higher xylose concentration was impaired as compared to the wild-type strain (Fig. 3E). The S. cerevisiae ZNF1-overexpressing strain showed a similar pattern of cell survival as the wild-type strain in the spot test (Fig. 3E). The bud21D strain showed slightly increased cell survival when compared to the wild-type control, while the effect was further enhanced in the bud21 $1+\mathrm{pLJ} 529-Z N F 1$ strain (Fig. 3E), suggesting that combined genetic manipulation is more effective for increased cell survival. Importantly, the co-substrate of $0.05 \%(\mathrm{w} / \mathrm{v})$ glucose and xylose was essential and thus selected for subsequent investigations into xylose utilisation and xylitol production in the engineered S. cerevisiae strains.

\section{ZNF1 overexpression and BUD21 deletion increased xylose} to xylitol production

The general cellular response to alternative carbon sources includes an alteration in gene expression, which consequently reflects changes in metabolomic profiles. For example, the transition from glucose to xylose results in increased concentrations of amino acids and TCAcycle intermediates and decreased concentrations of sugar phosphates and redox cofactors [46]. The up-regulated expression of genes in the PPP are likely responsible for the observed alterations. Next, the metabolite profiles of the engineered $S$. cerevisiae strains during xylose fermentation were investigated at high xylose concentrations, i.e. $2 \%$ or $10 \%(\mathrm{w} / \mathrm{v})$ xylose mixed with $0.05 \%(\mathrm{w} / \mathrm{v})$ glucose (Table 1). The expression level of ZNF1 in the plasmid form of the BY4742+ pLJ529-ZNF1 strain was increased by approximately 13-fold as compared to the control BY4742 + pRS316 strain. It was also higher than that of the integrated ZNF1 strain, previously generated using the CRISPR technique (7.0-fold) [47]. Thus, the plasmid-derived ZNF1-overexpressing strain was chosen for further experiments to measure xylose utilisation and xylitol production. Notably, the ZNF1 gene was expressed under the strong TPI promoter in the BY4742+ pLJ529ZNF1 and bud21 + pLJ529-ZNF1 strains. The pRS316 plasmid was used as the empty vector, containing the URA3 gene as a selection marker, which affects cell growth. Therefore, growth and metabolite production was compared between strains that had undergone similar genetic manipulation using at least three different replicates from two independent experiments.

Under $2 \%(\mathrm{w} / \mathrm{v})$ xylose and $0.05 \%(\mathrm{w} / \mathrm{v})$ glucose mix conditions, xylose was completely used by day 10 of fermentation (Fig. 4A). Xylose consumption was highest in the bud21 $\Delta+$ pLJ529-ZNF1 strain at $0.09 \mathrm{~g} / \mathrm{L} / \mathrm{h}$ or approximately at a rate of $0.04 \mathrm{~g} / \mathrm{g} \mathrm{CDW} / \mathrm{h}$ when compared to BY4742+pRS316 (Table 1). Since Znf1 not only activated xylose reductase genes but also xylitol dehydrogenase genes (Additional file 1: Table S1 and Fig. 2D), xylitol was rapidly consumed by the engineered strain during xylose starvation (Fig. 4A). In the metabolic profiling of the $z n f 1 \Delta+$ pRS316 strain, carrying a deletion of the ZNF1 gene, it showed a decrease in xylitol yield by $5.26 \%$, or at $0.27 \mathrm{~g} / \mathrm{L}$ of maximum xylitol produced, compared with the wild-type strain with a yield of $0.29 \mathrm{~g} / \mathrm{L}$ of maximum xylitol produced from $2 \%$ xylose fermentation at day 8 (Table 1 ). However, overexpression of ZNF1 significantly increased the xylitol yield up to $68.42 \%$ or $0.48 \mathrm{~g} / \mathrm{L}$ xylitol when compared to the BY4742+pRS316 strain with a yield 

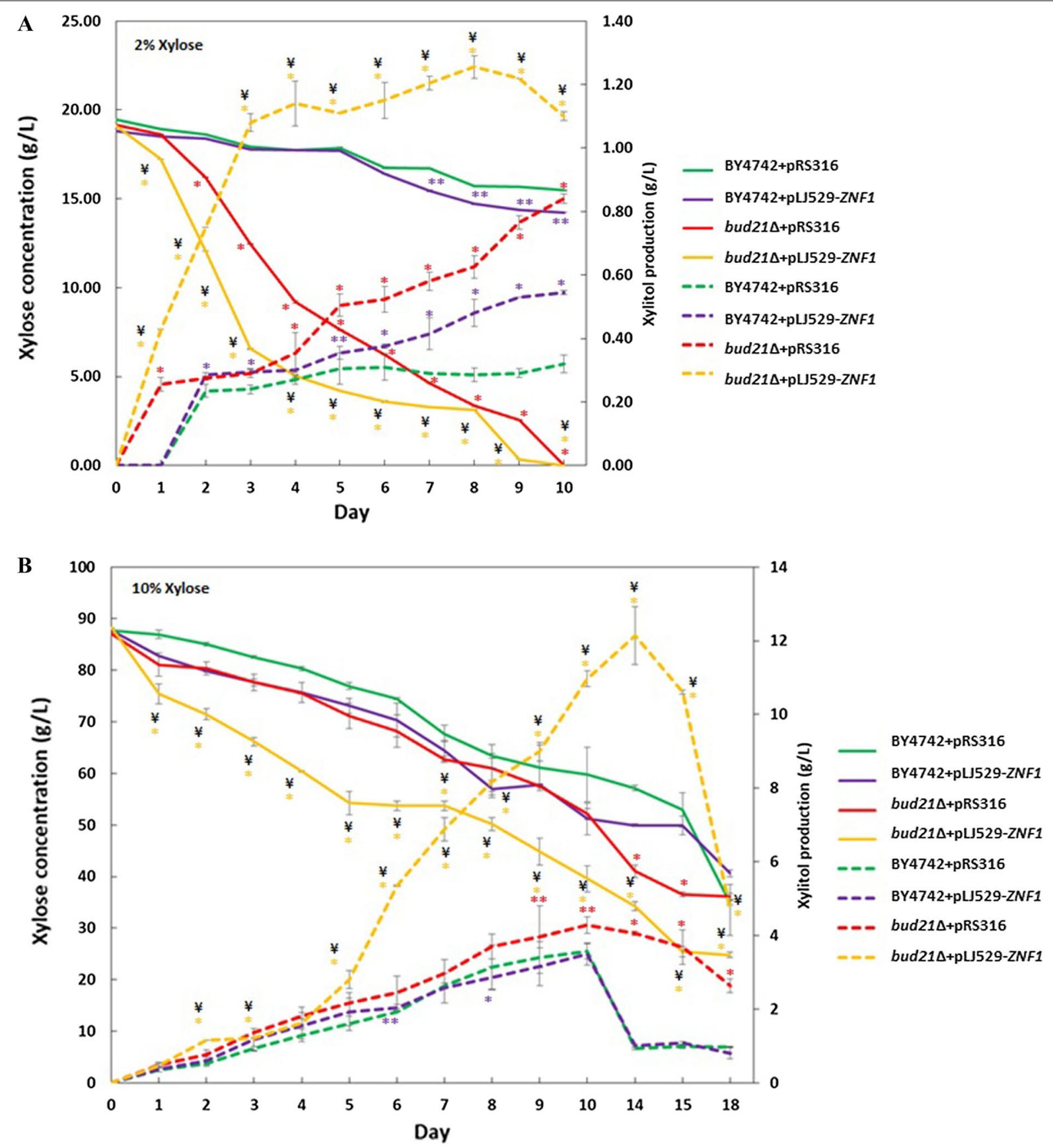

Fig. 4 Xylose fermentation profile and xylitol production of S. cerevisiae wild type and engineered strains. Different S. cerevisiae strains of BY4742 + pRS316, BY4742 + pLJ529-ZNF1, bud21 + pRS316, and bud21 + pL529-ZNF1 were grown under YPX supplemented with $\mathbf{A} 2 \%$ (w/v) or B $10 \%(\mathrm{w} / \mathrm{v})$ of xylose mixed with $0.05 \%$ glucose at $30^{\circ} \mathrm{C}$ for 10 or 18 days, respectively. For all plots presented, xylose concentration (g/L) (solid line), xylitol concentration ( $\mathrm{g} / \mathrm{L}$ ) (dashed line). Xylose consumption and xylitol concentrations were determined by HPLC, and data was based on two independent experiments conducted in triplicate. Error bars indicated standard deviations calculated from at least two independent experiments performed in triplicate. Significance differences were determined by one-way ANOVA with Tukey HSD method $\left({ }^{*}, p<0.05 ;{ }^{* *}, p<0.01\right.$, as compared to the control BY4742 + pRS316 strain or $¥, p<0.05$ as compared to the control bud21 + pRS316) 
of $0.29 \mathrm{~g} / \mathrm{L}$ xylitol (Table 1). The bud21 $\Delta+$ pRS316 strain, carrying a deletion of the $B U D 21$ gene, showed a greater increase in xylitol yield of $119.30 \%$, or $0.63 \mathrm{~g} / \mathrm{L}$ of maximum xylitol produced at day 8 when compared to the wild-type strain (Table 1 ). Interestingly, the bud21 $\Delta+$ pLJ529-ZNF1 strain consumed xylose much faster than the bud21 $\Delta+$ pRS316 strain, with a significantly increased xylitol yield of $340.35 \%$, i.e. $1.26 \mathrm{~g} / \mathrm{L}$ xylitol or $0.08 \mathrm{~g}$ of xylitol/g of consumed xylose (Table 1 ) or approximately 6 -times higher than the wild-type stain. Overall, the results indicate that this engineering approach of ZNF1 overexpression and BUD21 deletion is promising for enhanced xylose fermentation.

Next, a higher concentration of xylose was used to augment xylitol production using a $0.05 \%(\mathrm{w} / \mathrm{v})$ glucose and $10 \%(\mathrm{w} / \mathrm{v})$ xylose mix. At this xylose concentration, over $60 \%$ of xylose was used by the wild-type $S$. cerevisiae at the end of fermentation on day 18 (Fig. 4B). Similarly, at day 14 , the $z n f 1 \Delta+$ pRS316 strain showed a decrease in xylitol yield by $46.81 \%$, or $0.50 \mathrm{~g} / \mathrm{L}$ of maximum xylitol produced, compared with the wildtype strain with a yield of $0.94 \mathrm{~g} / \mathrm{L}$ of maximum xylitol produced (Table 1). Overexpression of ZNF1 significantly increased the xylitol yield by $6.95 \%$, or $1.00 \mathrm{~g} / \mathrm{L}$ xylitol and consumed xylose at $0.11 \mathrm{~g} / \mathrm{L} / \mathrm{h}$, comparable to the wild-type strain (Fig. 4B and Table 1). The bud21 + pRS316 strain showed an increase in xylitol yield by $334.22 \%$, or $4.06 \mathrm{~g} / \mathrm{L}$ of maximum xylitol produced, which is 4.0 -fold higher than the wild-type strain at day 14 (Table 1). Interestingly, the bud21 $\Delta+$ pLJ529ZNF1 strain consumed xylose much faster than the other strains at a rate of $0.16 \mathrm{~g} / \mathrm{L} / \mathrm{h}$, with a significantly increased xylitol yield of $1,198.90 \%$, or $12.14 \mathrm{~g} / \mathrm{L}$ xylitol (Table 1), i.e. 12-fold higher than the wild-type strain, supporting the current engineering approach to high xylose to xylitol bioconversion. Notably, during days 10 to 14 of fermentation, xylitol production declined, suggesting the consumption of xylitol as another source of carbon (Fig. 4B). This was observed for all tested strains, especially those overexpressing Znf1, suggesting its role in the conversion of xylitol to xylulose and other downstream metabolites.

Additionally, regarding cell growth, the $z n f 1 \Delta+\mathrm{pRS} 316$ strain displayed a significant decrease in biomass by $32.31-46.17 \%$ and a biomass specific rate of $0.003 \mathrm{~g} / \mathrm{L} / \mathrm{h}$ while the overexpressing BY4742+ pLJ529-ZNF1 strain showed lower cell growth by $3.67-10.78 \%$ and biomass specific rates of $0.003-0.005 \mathrm{~g} / \mathrm{L} / \mathrm{h}$ when compared to the BY4142+pRS316 strain with biomass specific rates of $0.004-0.005 \mathrm{~g} / \mathrm{L} / \mathrm{h}$ (Table 1 ). However, the bud21 + pRS316 strain, which lacks the ribosomal subunit Bud21, displayed a significant increase in biomass by $13-68.48 \%$ with biomass specific rates of $0.004-0.009 \mathrm{~g} / \mathrm{L} / \mathrm{h}$. Further, biomass increased by $114.90-120.81 \%$ and higher biomass specific rates of $0.009-0.011 \mathrm{~g} / \mathrm{L} / \mathrm{h}$ were found in the bud21 $\Delta+\mathrm{pLJ} 529$ ZNF1 strain (Table 1). Overall, these results indicate that the transcription factor Znf1 and the xylose suppressor Bud21 affect cell growth and biomass generation during fermentation in xylose.

\section{Comparative proteome analysis of engineered S. cerevisiae strains during xylose utilisation}

Proteomic profiles of some selected $S$. cerevisiae strains, namely BY4742, BY4742+ pLJ529-ZNF1, and bud21 + pLJ529-ZNF1 during growth in YP media containing $0.05 \%$ glucose $(\mathrm{w} / \mathrm{v})$ mixed with or without $2 \%$ xylose $(\mathrm{w} / \mathrm{v})$ were obtained at $48 \mathrm{~h}$ of fermentation at the highest rate of xylose consumption and no glucose to investigate differential changes in protein expression. A total of 267 differentially expressed proteins were identified, as listed in Tables 2 and 3. The relative quantity was indicated in term of protein fold-change significantly at the $95 \%$ confidence level $(P<0.05)$ in triplicate samples. During xylose utilisation, alterations in the protein profile were observed for many genes involved in xylose metabolism, the PPP, hexose transport, and other related pathways (Tables 2 and 3). For example, a large number of proteins related to ribosomal proteins and translation, including the ribosomal 40S subunit (Rps10a, Rps10b, Rps12, Rps13, Rps15, Rps18a, Rps18b, Rsp22a, Rps22b, Rps25a, Rps25b, Rps3, Rps4a, Rps4b), the ribosomal 60S subunit (Rpl1a, Rpl1b, Rpl20a, Rpl20b, Rpl23a, Rpl30, Rpl31a, Rpl32, Rpl4a, Rpl4b, Rpl6a, Rpl9a, and Rpl9b), the ubiquitin-ribosomal 40S subunit (Rps31), the ubiquitin-ribosomal 60S subunit (Rpl40a, and Rpl40b), and translation elongation factor (Eft1, Gcd11, Efb1, Cam1, Tef1, Yef3, Tef4, and Tif1) were affected as their levels of protein expression were differentially increased (>twofold) in bud21 + pLJ529-ZNF1 (Table 3). These proteomic results indicate that xylose metabolism is tightly associated with ribosomal protein synthesis. ZNF1 and BUD21 appear to play a key role in finetuning protein synthesis during the utilisation of alternative sugars. Recently, the overexpression of RPL9A, $R P L 7 B$, and $R P L 7 A$ was shown to increase the specific xylose utilisation rate by $6-21 \%$ [29], and they were also regulated by these two modulators. In addition, expression levels of many enzymes involved in glycolysis were altered by xylose and depended greatly on Znf1 and Bud21. These were key metabolic enzymes of glycolysis, including Pfk1, Pfk2, Glk1, Tdh3, Hxk1, Hxk2, Pgk1, Eno1, Eno2, Pdb1, Pyk1, Pdc1, Pdc5, and Pdc6, and TCA enzymes such as Aco1, Cit1, and Lat1, which were 
Table 2 Proteomic profiles of central carbon metabolism of S. cerevisiae strains BY4742, BY4742+ pLJ529-ZNF1, and the bud21 $1+$ pLJ529-ZNF1 during fermentation of mixed $0.05 \%$ glucose $(\mathrm{w} / \mathrm{v})$ with or without $2 \%$ xylose $(\mathrm{w} / \mathrm{v})$ at $48 \mathrm{~h}$

\begin{tabular}{|c|c|c|c|c|c|}
\hline \multicolumn{2}{|c|}{ Description/strain } & \multicolumn{4}{|c|}{ Protein fold-change in xylose versus no xylose condition } \\
\hline \multirow[t]{2}{*}{ Protein } & \multirow[t]{2}{*}{ Function } & \multirow[t]{2}{*}{ BY4742 } & \multirow{2}{*}{$\begin{array}{l}\text { BY4742 } \\
+ \text { pLJ529-ZNF1 }\end{array}$} & \multirow{2}{*}{$\begin{array}{l}\text { bud21 } \\
\text { + pLJ529-ZNF1 }\end{array}$} & \multirow[t]{2}{*}{$p$-value } \\
\hline & & & & & \\
\hline \multicolumn{6}{|c|}{ Glycolysis/Gluconeogenesis/TCA cycle } \\
\hline Pfk1 & 6-phosphofructokinase 1 and 2 & $0.91-0.96$ & $0.34-0.59$ & $1.95-3.50$ & $<0.05$ \\
\hline Fba1 & Fructose-bisphosphate aldolase & 1.04 & 0.86 & 1.69 & $<0.05$ \\
\hline Glk1 & Glucokinase & 0.89 & 0.51 & 4.85 & $<0.05$ \\
\hline Pgi1 & Glucose-6-phosphate isomerase & 1.39 & 1.05 & 1.91 & $<0.05$ \\
\hline Tdh1-3 & Glyceraldehyde-3-phosphate dehydrogenase 1-3 & $0.87-0.88$ & $0.74-1.34$ & $1.23-1.90$ & $<0.05$ \\
\hline $\mathrm{Hxk} 1,2$ & Hexokinase 1 and 2 & $1.04-1.29$ & $0.20-0.29$ & $4.01-8.02$ & $<0.05$ \\
\hline Pgk1 & Phosphoglycerate kinase & 1.11 & 0.55 & 2.51 & $<0.05$ \\
\hline Gpm1 & Phosphoglycerate mutase & 0.93 & 1.1 & 1.39 & $<0.05$ \\
\hline Eno1, 2 & Enolase 1 and 2 & $0.93-0.94$ & 0.3 & $2.57-2.73$ & $<0.05$ \\
\hline Pdb1 & Pyruvate dehydrogenase & 1.28 & 0.98 & 4.25 & $<0.05$ \\
\hline Pyk1 & Pyruvate kinase & 0.89 & 0.57 & 2.42 & $<0.05$ \\
\hline Tpi1 & Triose-phosphate isomerase & 1.28 & 0.72 & 2.02 & $<0.05$ \\
\hline $\operatorname{Pdc} 1,5,6$ & Pyruvate decarboxylase 1,5 , and 6 & $0.66-0.79$ & $0.37-0.52$ & $1.74-3.37$ & $<0.05$ \\
\hline Acol & Aconitate hydratase & 0.98 & 0.66 & 2.92 & $<0.05$ \\
\hline Cit1 & Citrate synthase & 0.81 & 0.56 & 3.27 & $<0.05$ \\
\hline Lat1 & Dihydrolipoyllysine-residue acetyltransferase & 0.76 & 0.8 & 3.09 & $<0.05$ \\
\hline Mdh1 & Malate dehydrogenase & 1.33 & 1.05 & 1.86 & $<0.05$ \\
\hline Pck1 & Phosphoenolpyruvate carboxykinase & 0.33 & 0.5 & 1.18 & $<0.05$ \\
\hline \multicolumn{6}{|c|}{ Pentose phosphate pathway and Oxidoreductase } \\
\hline Adh1, 2 & Alcohol dehydrogenase 1 and 2 & $0.74-0.98$ & $0.90-1.16$ & $1.05-2.45$ & $<0.05$ \\
\hline Gnd1 & Phosphogluconate dehydrogenase & 0.95 & 0.77 & 2.67 & $<0.05$ \\
\hline YDL124W & Aldo-keto reductase & 0.71 & 0.3 & 3.73 & $<0.05$ \\
\hline Tal1 & Transaldolase & 0.93 & 0.4 & 2.11 & $<0.05$ \\
\hline Tkl1 & Transketolase & 1.37 & 0.87 & 2.04 & $<0.05$ \\
\hline \multicolumn{6}{|c|}{ Hexose transport } \\
\hline Hxt1-7 & Hexose transporter & $1.36-1.76$ & $0.57-0.82$ & $3.49-10.43$ & $<0.05$ \\
\hline
\end{tabular}

suppressed by the presence of Znf1 despite the absence of glucose, as shown by low protein levels in the ZNF1overexpressing strain. In contrast, increased protein levels of some gluconeogenic enzymes such as Tdh $1 / 2$ was also observed in the ZNF1-overexpressing strain, indicating a tight regulation of carbon source utilisation in the absence of glucose (Table 2). However, these protein levels were increased following BUD21 deletion during xylose utilisation after the post-glucose effect (Tables 2 and 3). In support of this, utilisation of xylose requires glucose-6-phosphate generated from gluconeogenesis and NADPH from the oxidation of G6P via the PPP in response to xylose [48], which was enhanced in the strain lacking the Bud21 suppressor of xyloseutilising proteins (Table 2). Deletion of BUD21 was also required for increased levels of alcohol dehydrogenase Adh1 during alcoholic fermentation and Gnd1, Tal1, and Tkl1 of the PPP as well as a less known aldo-keto reductase Ydl124w that is involved in the bioconversion of xylose to xylitol (Table 2), supporting the critical role of Bud21 in xylose utilisation.

Moreover, the levels of hexose transporters (Hxt1, $2,3,5,6$, and 7) were decreased in the ZNF1-overexpressing strain as compared to the wild-type strain BY4742 (Table 2), suggesting a repressive role of $\mathrm{Znf1}$ on the transport of glucose during co-fermentation in the xylose utilising step. Interestingly, dramatically increased protein levels (by approximately tenfold) were observed in the bud21 $\Delta+$ pLJ529-ZNF1 strain 
Table 3 Proteomic profiles of ribosomal proteins and translation of S. cerevisiae strains BY4742, BY4742 + pLJ529-ZNF1, and the bud21 $1+$ pLJ529-ZNF1 during fermentation of mixed $0.05 \%$ glucose $(\mathrm{w} / \mathrm{v})$ with or without $2 \%$ xylose $(\mathrm{w} / \mathrm{V})$ at $48 \mathrm{~h}$

\begin{tabular}{|c|c|c|c|c|c|}
\hline \multicolumn{2}{|c|}{ Description/strain } & \multicolumn{4}{|c|}{ Protein fold-change in xylose versus no xylose condition } \\
\hline Protein & Function & BY4742 & $\begin{array}{l}\text { BY4742 } \\
+ \text { pLJ529-ZNF1 }\end{array}$ & $\begin{array}{l}\text { bud21 } \\
+ \text { pLJ529-ZNF1 }\end{array}$ & $p$-value \\
\hline \multicolumn{6}{|c|}{ Ribosomal protein and translation } \\
\hline Tma19 & Protein that associates with ribosomes & 0.99 & 0.65 & 2.96 & $<0.05$ \\
\hline Eft1 & Elongation factor 2 & 0.78 & 0.44 & 2.2 & $<0.05$ \\
\hline Gcd11 & Translation initiation factor elF2 subunit gamma & 0.78 & 0.44 & 2.2 & $<0.05$ \\
\hline YNL208W & Hypothetical protein interacts with ribosomes & 1.24 & 1.28 & 1.69 & $<0.05$ \\
\hline Dug1 & Metallodipeptidase & 0.86 & 0.84 & 2.62 & $<0.05$ \\
\hline Efb1 & Translation elongation factor 1 subunit beta & 0.73 & 0.23 & 6.02 & $<0.05$ \\
\hline Cam1 & Translation elongation factor EF1B gamma & 1.15 & 0.73 & 2.64 & $<0.05$ \\
\hline Arc1 & Protein that binds tRNA & 1.4 & 1.07 & 3.2 & $<0.05$ \\
\hline Rim1 & Single-stranded DNA-binding protein & 1.15 & 1.9 & 2.06 & $<0.05$ \\
\hline Pab1 & Polyadenylate-binding protein & 0.94 & 0.98 & 1.51 & $<0.05$ \\
\hline Rps0-30 & Ribosomal $40 S$ subunit protein $A$ and $B$ & $0.24-2.04$ & $0.37-1.42$ & $0.40-4.70$ & $<0.05$ \\
\hline Rpl1-43 & Ribosomal 605 subunit protein $A$ and $B$ & $0.45-1.33$ & $0.44-2.02$ & $0.56-2.69$ & $<0.05$ \\
\hline Rpp0-1 & Ribosomal protein $\mathrm{P0}$ and $\mathrm{P} 1 \mathrm{~B}$ & 1.09 & 1.11 & $2.83-5.08$ & $<0.05$ \\
\hline Tef1 & Translation elongation factor EF-1 alpha & 1.05 & 0.89 & 1.75 & $<0.05$ \\
\hline Yef3 & Translation elongation factor EF-3 & 1.05 & 0.89 & 2.66 & $<0.05$ \\
\hline Tef4 & Translation elongation factor EF1B gamma & 0.97 & 0.73 & 2.6 & $<0.05$ \\
\hline Tif1 & Translation initiation factor elF4A & 0.97 & 0.73 & 2.37 & $<0.05$ \\
\hline Rps31 & Ubiquitin-ribosomal $40 S$ subunit & 1.11 & 0.97 & 1.72 & $<0.05$ \\
\hline Rpl40 & Ubiquitin-ribosomal 605 subunit $A$ and $B$ & 1.11 & 0.97 & 2.61 & $<0.05$ \\
\hline
\end{tabular}

for most Hxts, including Hxt2 and Hxt7, which are required for xylose uptake (Table 2).

\section{Improved tolerance to lignocellulosic inhibitors in the engineered bud21 + pLJ529-ZNF1 strain}

Xylitol production is also affected by intracellular pools of NADPH and NADH as well as the presence of inhibitory compounds produced during chemical hydrolysis or pretreatment. An additional detoxification step is normally required unless inhibitor tolerant yeast strains are employed. Thus, the involvement of the Znf1 transcription factor in mediating tolerance to lignocellulosic inhibitors was investigated. Deletion of the ZNF1 gene was found to dramatically impair the growth of yeast cells on $10 \%$ xylose-containing YPD plates with the addition of lignocellulose inhibitors such as $40 \mathrm{mM}$ formic acid (FA), $20 \mathrm{mM}$ furfural (FF), or $85 \mathrm{mM}$ levulinic acid (LA) (Fig. 5A). However, the S. cerevisiae ZNF1-overexpressing strain displayed better growth as compared to the wild-type strain in the presence of FA and LA (Fig. 5A).

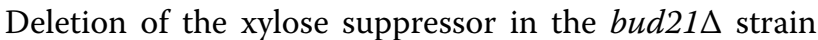
did not significantly improve cell growth, while the bud21 $\Delta+$ pLJ529-ZNF1 strain showed maximal growth as compared the other strains (Fig. 5A). To confirm, spot assays were also performed in the presence of lignocellulose inhibitors. The most severe impairment was found in the $z n f 1 \Delta$, wild-type, bud21 $\Delta$ and $b u d 21 \Delta+$ pLJ529ZNF1 strains, respectively (Fig. 5B).

Furthermore, CFU assays were conducted to assess cell survival, which may not obviously be observed by spot tests. At day 3 of incubation under high xylose conditions (top right panel), the $z n f 1 \Delta+\mathrm{pRS} 316$ strain showed dramatically decreased cell growth and fewer colonyforming units $(\mathrm{CFU} / \mathrm{mL})$ of $7.75 \times 10^{6}$ as compared to the wild-type strain with a CFU of $8.18 \times 10^{6}$ (Fig. 5C) Additionally, the bud21 + pLJ529-ZNF1 strain displayed a significant increase in CFU to $8.53 \times 10^{6}$, while the control strain BY4742+pRS316, the bud21 $1+$ pRS316 strain, and the BY4742+ pLJ529-ZNF1 strain had CFU values of $8.18,8.29 \times 10^{6}$, and $8.29 \times 10^{6}$, respectively (Fig. 5C). With regard to the effect of the inhibitors, the formation of acids and furan aldehydes resulted in decreased sugar yields. In the presence of $40 \mathrm{mM} F A$, the bud21 $\Delta+$ pLJ529-ZNF1 strain displayed a significant increase in CFU to $8.14 \times 10^{6}$ as compared to the other strains (Fig. 5C). Finally, in $20 \mathrm{mM}$ FF treated cells at day 4 

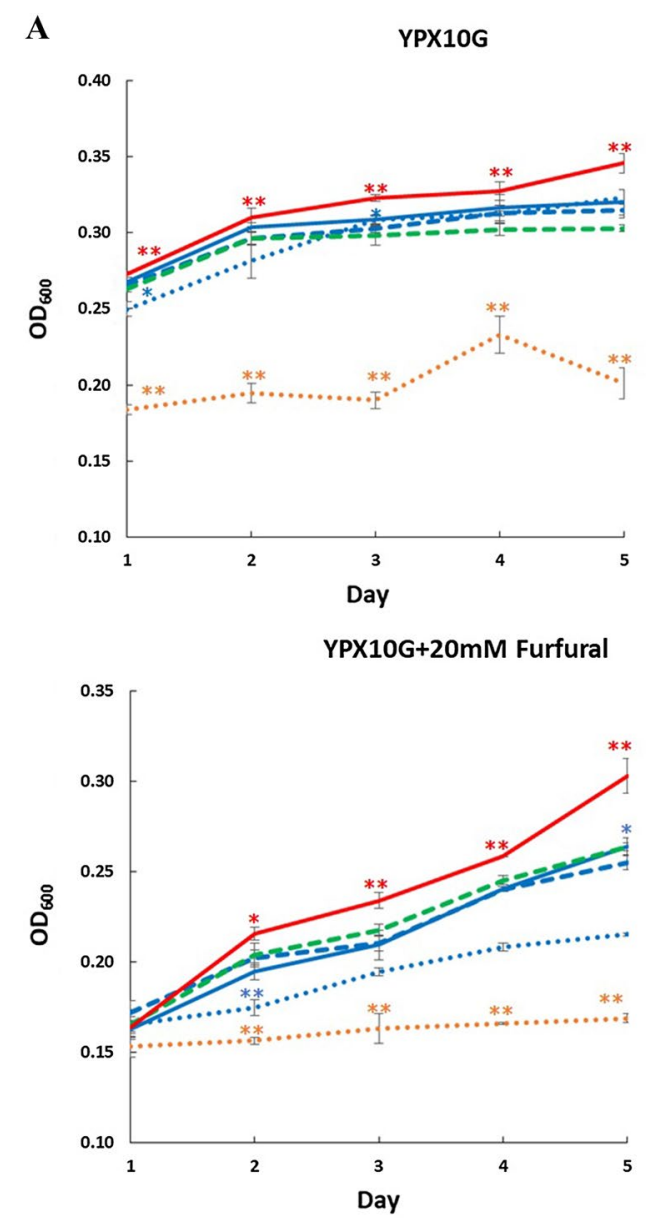

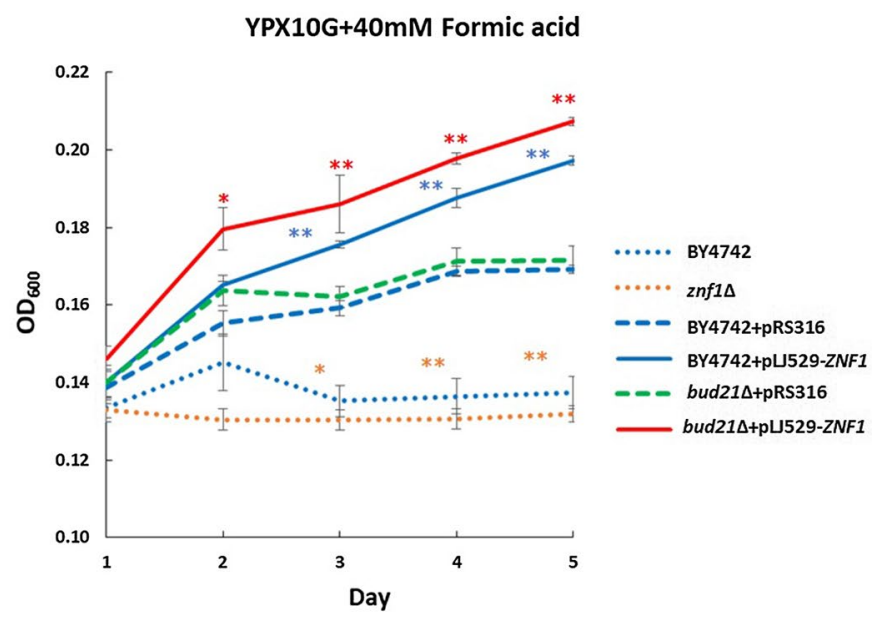

YPX10G+85mM Levulinic acid

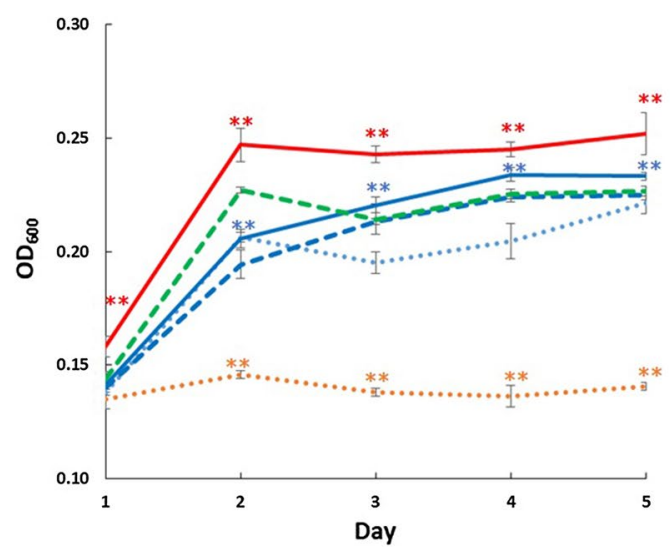

Fig. 5 Overexpression of ZNF1 and deletion of BUD21 genes conferred tolerance to furfural and lignocellulosic acids stress. The $S$. cerevisiae wild-type BY4742, the znf1 $\triangle$, the BY4742 + pRS316, the BY4742 + pLJ529-ZNF1, the bud21 + pRS316 and bud21 + pLJ529-ZNF1 strains were examined for growth and cell survival. A Growth assays were conducted. Cells were grown in YPX10 media containing 10\% xylose (W/V) and 0.05\% glucose plus $20 \mathrm{mM}$ furfural (FF), $40 \mathrm{mM}$ formic acid (FA), or $85 \mathrm{mM}$ levulinic acid (LA). Growth of strains were monitored and expressed as the optical density values $\left(\mathrm{OD}_{600}\right)$ for 5 days at $30^{\circ} \mathrm{C}$. B Spot tests of different S. cerevisiae strains were examined on $\mathrm{YPX} 10$ plates containing $10 \%$ xylose (w/v) and $0.05 \%$ glucose to monitor cell survival in the presence of $35 \mathrm{mM}$ formic acid, $20 \mathrm{mM}$ furfural, or $85 \mathrm{mM}$ levulinic acid. Ten-fold serial dilutions of cells were spotted on plates and incubated at $30^{\circ} \mathrm{C}$ for $2-3$ days. C Cell survival was analyzed using CFU/ml method. Significance differences were determined by one-way ANOVA with Tukey HSD method $\left({ }^{*}, p<0.05 ; *^{* *}, p<0.01\right)$ as compared to the controls BY4742 or BY4742 + pRS316. Error bars indicated standard deviation (SD)

of incubation, the $z n f 1 \Delta+$ pRS316 strain showed dramatically decreased cell growth and fewer colony-forming units (CFU) at $7.26 \times 10^{6}$, while the bud21 + pLJ529ZNF1 strain displayed a significant increase in CFU to $7.94 \times 10^{6}$ as compared to the other strains (Fig. 5C). Overall, these results indicate the increased cell viability of the $b u d 21 \Delta+$ pLJ529-ZNF1 strain as shown by significantly increased growth, cell survival, and CFU numbers. Thus, the engineered strain may be applicable for xylose fermentation using acid pretreatment.

\section{Conversion of xylose to xylitol from rice straw hydrolysate} Here, as proof of principle, xylitol was produced using rice straw hydrolysate as a cheap and abundant agricultural waste. The strategy was to combine bioconversion with a pretreatment step using the engineered yeast strains with an enhanced ability to utilise relevant xylose substrates. First, the fungus Xylaria sp. BCC 1067, a wood-decaying fungus, was cultivated under solid state fermentation (SoSF) with $70 \%$ moisture for 28 days as the biological pretreatment step 


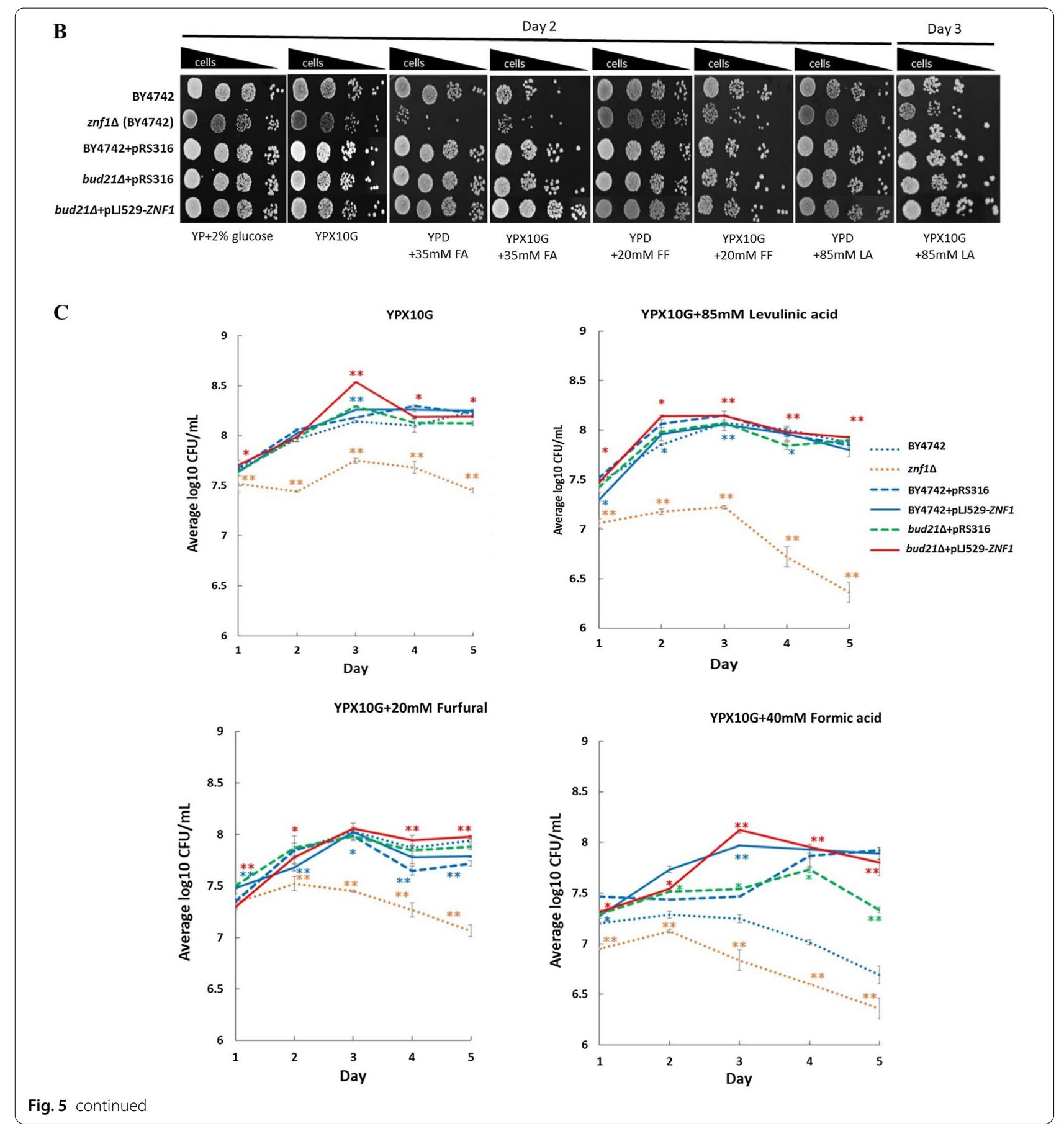

with a low-cost and eco-friendly approach. The highest xylanase activity of $48.66 \pm 0.73 \mathrm{U} / \mathrm{g}$ of rice straw was obtained at day 14 , which rapidly decreased to $22.80 \pm 0.91 \mathrm{U} / \mathrm{g}$ of rice straw after 28 days (Fig. 6A). The results of xylanase production are shown after 14 days of cultivation (Fig. 6A). Likewise, cellulase production between days 7 and 14 of fermentation was
$6.02 \pm 0.87$ to $6.19 \pm 0.68 \mathrm{U} / \mathrm{g}$ of rice straw (Fig. 6A). The maximum cellulase production was observed after 21 days at $11.04 \pm 0.06 \mathrm{U} / \mathrm{g}$ of rice straw (Fig. 6A). Almost all enzyme production was decreased after 14 and 21 days, respectively, which may be due to a reduction in the hemicellulose content, followed by the cellulose content. The fungus Xylaria produced 
more xylanase than cellulase (Fig. 6A). The maximum xylose concentration of $107.7 \pm 5.35 \mathrm{mg} / \mathrm{g}$ of rice straw was obtained after 14 days of fermentation (Fig. 6A). The highest glucose concentrations of 31.10 and $32.63 \mathrm{mg} / \mathrm{g}$ of rice straw were detected after 14 and 21 days, respectively (Fig. 6A).

To start fermentation, yeast cells were provided with an additional $250 \mathrm{mg} / \mathrm{L}$ of glucose to obtain an initial glucose concentration of $750.0 \mathrm{mg} / \mathrm{L}$, while the xylose and xylitol concentrations were started at 50.0 and $44.0 \mathrm{mg} / \mathrm{L}$, respectively. Here, all tested strains consumed glucose similarly within $36 \mathrm{~h}$ (Fig. 6B), indicating that glucose was the first carbon source consumed, and followed by the activation of xylose metabolism. The combined bud21 + pLJ529-ZNF1 strain completely consumed xylose within the first $12 \mathrm{~h}$, much faster than the control BY4742 + pRS316 strain, in which only $30 \%$ of xylose was consumed after $60 \mathrm{~h}$ (Fig. 6B). Implementation of the engineered strain bud21 $\Delta+$ pLJ529-ZNF1 allowed for the production of xylitol. This was found to be $50 \mathrm{mg} / \mathrm{L}$ or $0.12 \mathrm{~g} / \mathrm{g}$ of Xylaria-pretreated rice straw hydrolysate with supplemented nutrients at $12 \mathrm{~h}$, while no xylitol production was observed with other strains (Fig. 6B). Nevertheless, all strains consumed xylitol

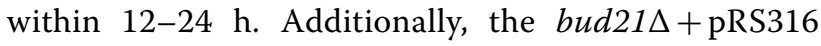
strain displayed a significant increase in biomass of $219.12 \%$ or $1.04 \mathrm{~g} / \mathrm{L}$ when compared to the wild-type strain, while bud21 + pLJ529-ZNF1 displayed a significant increase in biomass of $234.87 \%$ or $1.12 \mathrm{~g} / \mathrm{L}$ as compared to the control strain at $60 \mathrm{~h}$ (Fig. 6B). Overall, these results confirm the role of the transcription factor Znf1 and the xylose suppressor Bud21 in xylose utilisation and xylitol production.

\section{Discussion}

A better understanding of the transcriptional control of xylose-induced metabolic reprogramming in yeasts will allow for the optimisation of yeast-based bioprocesses to produce biofuels and chemicals using the most abundant sugars available on earth, glucose and xylose. In this study, we characterised the roles of the key transcription factor Znf1 in xylose metabolism by S. cerevisiae, and potential use of xylose as a carbon source to produce xylitol as an example. It appears that the expression of genes and proteins involved in xylose utilisation, glucose repression, and ribosomal protein synthesis is mediated by the common transcription regulator $\mathrm{Znf1}[26,28]$ (Tables 2 and 3). The first two processes are regulated in a concerted fashion to allow for appropriate utilisation of available alternative carbon sources for environmental stress adaptation, and largely depend on the transcription factor Znf1 and its key target protein Bud21. Investigation of xylose utilisation by $S$. cerevisiae and other yeasts indicates a global rewiring of metabolic networks with distinct transcriptional and metabolic patterns to glucose-mediated repression [49].

Importantly, the overexpression ZNF1 or deletion of $B U D 21$ has a significantly positive effect on xylose utilisation and xylitol production. Previously, using YE media containing $20 \mathrm{~g} / \mathrm{L}$ xylose, S. cerevisiae strain YKB2680, carrying the plasmid $\mathrm{p} X Y L A$ and $X K S 1$ encoding $\mathrm{XI}$ and xylulokinase, produced approximately $0.58 \mathrm{~g} / \mathrm{L}$ xylitol $(0.029 \mathrm{~g} / \mathrm{g}$ xylose consumed $)$ while the parental strain showed no xylitol production [22]. Recently, the S. cerevisiae strain Y-50463 that contains a synthesised yeast codon optimised for the XI gene $Y X I$ and a plasmid carrying a set of heterologous xylose utilisation genes of $S$. stipitis produced approximately $6 \mathrm{~g} / \mathrm{L}$ xylitol $(0.24 \mathrm{~g} / \mathrm{g}$ xylose consumed) in mixed glucose and $25 \mathrm{~g}$ xylose fermentation under aerobic conditions [43]. Notably, in our study, the bud21 $1+\mathrm{pLJ529-ZNF1} \mathrm{strain} \mathrm{produced}$ a higher yield of xylitol at $12.14 \mathrm{~g} / \mathrm{L}$ using mixed glucose and $100 \mathrm{~g}$ xylose $(0.23 \mathrm{~g} / \mathrm{g}$ xylose consumed) when compared to other engineered strains of $S$. cerevisiae, although less than the native xylose assimilating strains with $0.25-0.6 \mathrm{~g} / \mathrm{g}$ xylose consumed; therefore, additional improvements such as engineering strategies or optimised fermentation processes are required.

In support, the wild-type S. cerevisiae strain Y133 was shown to have significantly increased mRNA levels of ZNF1 and BUD21 during anaerobic xylose growth from RNA-seq data [33]. Regarding to the role of Bud21 in xylose to xylitol bioconversion, little is known regarding the involvement of this poorly described protein. Bud21 is involved in ribosomal protein biogenesis and processing, as well as responding to oxidative stress conditions [50]. This may explain its contribution to the enhanced biomass of cells. In addition, Bud21 also inhibits xylose fermentation [22]. A previous study reported that deletion of BUD21 strongly increases the level of Ty1 RNA by 33-fold and positively affects xylose utilisation [51]. Moreover, Bud21 phosphorylates Ira2, encoding GTPaseactivating proteins (GAPs) that negatively regulate the Ras pathway or act as inhibitors of the Ras pathway, leading to an increase in the anaerobic specific xylose consumption rate [52]. Accordingly, the ira $2 \Delta$ strain also showed increased sugar uptake rate during growth at a high xylose concentration of $50 \mathrm{~g} / \mathrm{L}$ [53]. Thus, it appears that Bud21 may function to suppress xylose utilisation. Importantly, the proteomic profiles of strains with bud21 deletion strongly enhanced the protein levels of many ribosomal protein and translation elongation factors as part of the post-glucose effect (Table 3). Increased expression levels of some ribosomal protein have been shown to enhance xylose utilisation [29]. In addition, the transcription factor Znf1 exerted unexpected roles 
$\mathbf{A}$

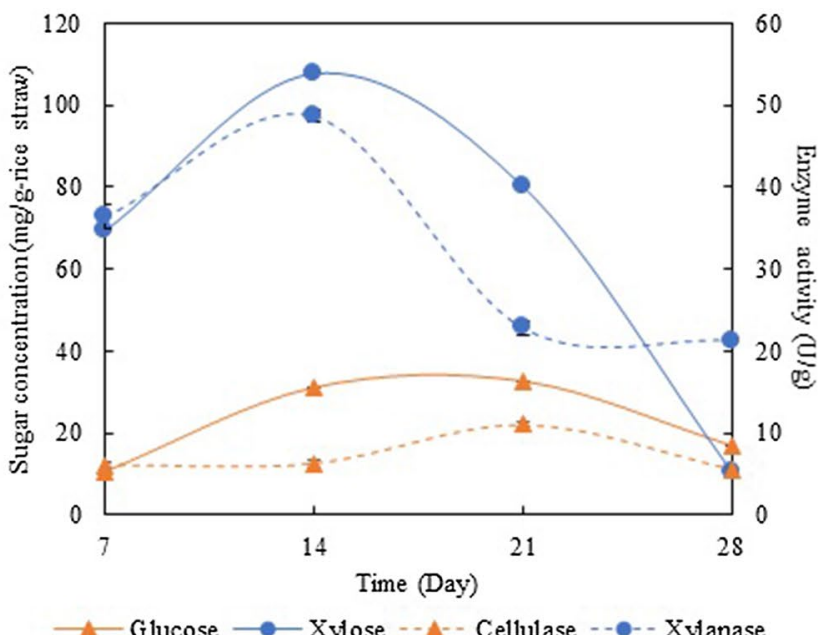

60

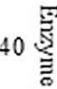

30 है.

20 ?ำ

10
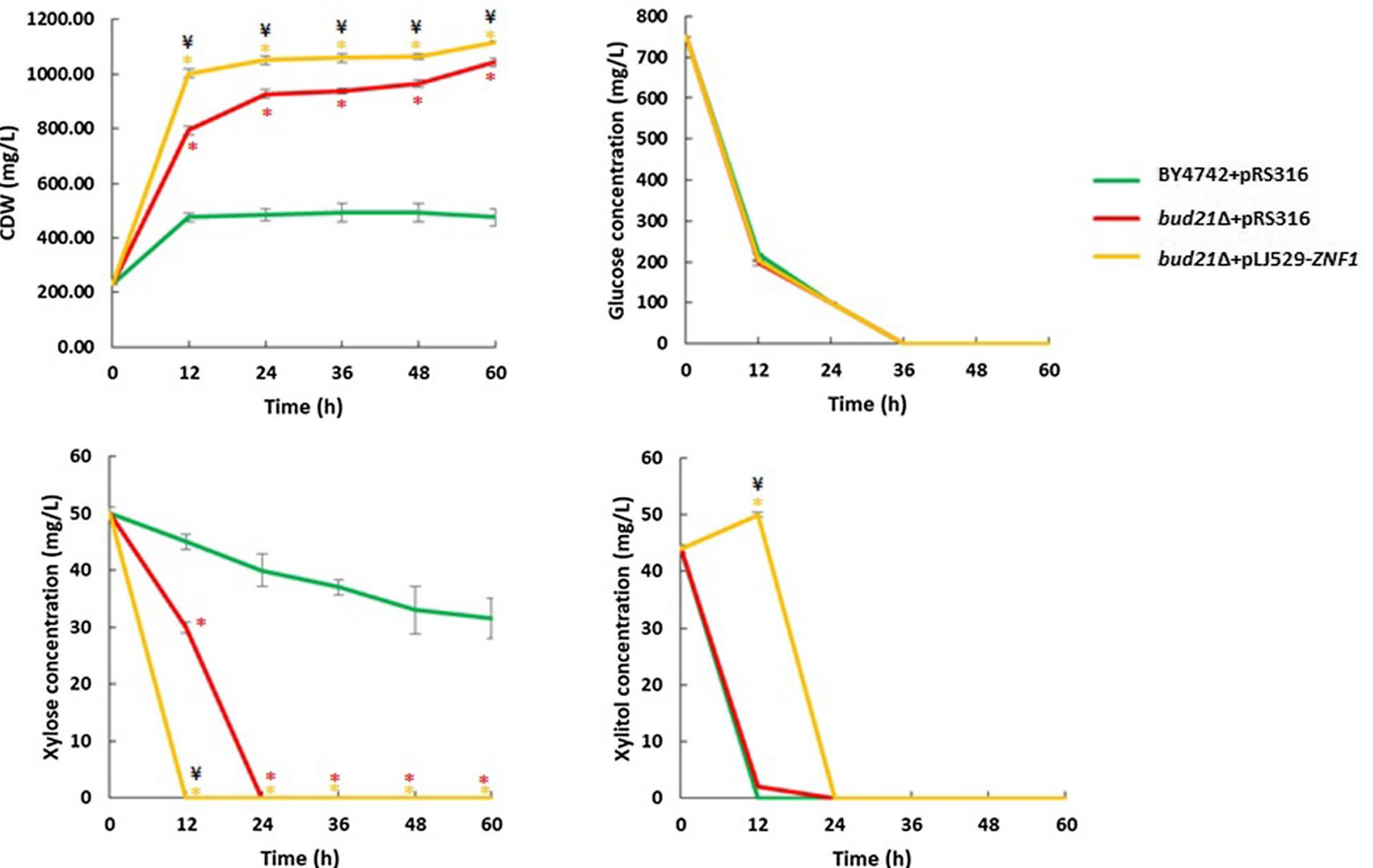

Fig. 6 Solid state fermentation of rice straw pretreated with Xylaria sp. BCC1067 for xylose to xylitol conversion. A Enzyme activity of cellulase and xylanase $(\mathrm{U} / \mathrm{g}$ ) and sugar concentration ( $\mathrm{mg} / \mathrm{g}$ of rice straw) under solid-state fermentation. Rice straw was pretreated with fungi Xylaria sp. BCC 1067 cultivated for 28 days at $25^{\circ} \mathrm{C}$ at $70 \%$ moisture content for 28 days. The reaction mixture was incubated at $50{ }^{\circ} \mathrm{C}$ for $10 \mathrm{~min}$. The reducing sugars released were quantified using glucose or xylose as a standard. B Conversion of xylose to xylitol from rice straw hydrolysate. The BY4742 + pRS316, the BY4742 + pLJ529-ZNF1, the bud21 + pRS316, and the bud21 + pLJ529-ZNF1 S. cerevisiae strains were grown using rice straw hydrolysate supplemented with YP medium and $0.05 \%$ glucose. Strains were incubated at $30^{\circ} \mathrm{C}$ with shaking for $60 \mathrm{~h}$. Glucose, xylose and xylitol concentrations were determined by HPLC and CDW (mg/L) was also obtained. Error bars indicated standard deviations calculated from at least two independent experiments performed in triplicate. Significance differences were determined by one-way ANOVA with Tukey HSD method ${ }^{*}$, $\left.\mathrm{p}<0.05 ;{ }^{*}, \mathrm{p}<0.01\right)$ or $(¥, \mathrm{p}<0.05)$ as compared to BY4742+pRS316 or bud21 $1+\mathrm{pRS} 316$, respectively 
during xylose utilisation in the absence of glucose by enhancing ribosome synthesis and altering cell metabolism, respectively. Znf1 exhibited low-level glycolysis and a de-repressed the TCA cycle, resembling glucose repression (Tables 2 and 3). Alteration of the metabolic state also affects glucose uptake, as shown by our and other studies. Different approaches to enhance xylose transport, including co-fermentation of xylose and other carbon sources, have been used to increase the utilisation of xylose [45]. In this study, co-fermentation with low glucose efficiently drove expression of the xylose transporters Hxt4, Hxt7, and Gal2 at the transcriptomic (Table 2 and Fig. 2) and the proteomic levels in the post-glucose effect (Table 3). Overall, overexpression of the transcription factor ZNF1 enhanced xylose utilisation, leading to induced expression of hexose/xylose transporters, altered hexokinase regulation as observed for Hxk1, and increased Znf1 target activation in various pathways mentioned above (Fig. 2D). Even though overexpression of ZNF1 in combination with deletion of the xylose suppressor BUD21 allowed for the activation of xylose metabolism and conferred a stress-tolerant improvement regarding lignocellulosic inhibitors, xylose uptake could be further improved, as shown by the proteomic data (Tables 2 and 3). It appears that glucose-sensing systems respond quite profoundly to alterations in the carbon source, including sugars. Additionally, inhibition of the downstream xylitol dehydrogenase enzymes for xylitol to xylulose conversion or xylulose kinase synthase (Xks1) (Additional file 1: Table S1, Figs. 1 and 2) may be necessary. In fact, the XKS1-deleted CK17 $X X K S 1$ S. cerevisiae strain shows a good capacity for the co-production of xylitol and ethanol using pretreated corn stover slurry [54]. Since most superior xylitol-producing natural strains are unsafe for use in the food and pharmaceutical industries, this engineered S. cerevisiae is promising for future xylitol production. It could be an alternative to the chemical route, which is associated with high costs and environmental damage [55]. To this end, this work will help in maintaining highly efficient xylose metabolism during glucose-xylose co-fermentation, which could be applied for the production of lignocellulosic bioethanol or other high-value bio-based fuels and biochemicals.

\section{Conclusion}

Znf1 is a key transcription factor that positively activates genes in various pathways of xylose metabolism during the transition from glucose to xylose and negatively inhibits the protein synthesis of some glycolytic and TCA enzymes as well as hexose transporters during xylose fermentation in the post-glucose effect to maintain glucose repression. Its main targets include genes in the
PPP, gluconeogenesis, glycolysis, gluconeogenesis as well as the TCA cycle and respiration required for oxidative metabolism, metabolite production, energy generation as well as ribosomal protein synthesis and translation in S. cerevisiae. Importantly, Znf1 also represses BUD21, whose expression is highly critical for xylose utilisation. A remarkable enhancement of xylitol production from xylose by the combination of ZNF1 overexpression and BUD21 deletion was ascribed to the activation of xylose reductases and increased xylose utilisation and blocked function of the xylose suppressor, respectively. A microbiological approach via the transcriptional control of xylose metabolism for further improvements in xylose utilisation from lignocellulosic biomass in yeasts has a promising future in support of the sugar industry and the global bioeconomy.

\section{Materials and methods}

\section{Strains and culture medium}

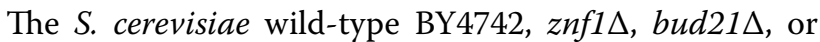
ZNF1-overexpressing strains were used for gene expression analysis, phenotypic analysis or fermentation assays (Additional file 2: Table 2). The ZNF1-overexpressing strain (BY4742+ pLJ529-ZNF1) was constructed using the empty plasmid pRS316 to create pLJ529+ZNF1 [56]. The plasmid pRS316 or pLJ529+ZNF1 (Table 4) was transformed into different $S$. cerevisiae strains using the LiAc/SS carrier via the PEG method [57]. Colonies were selected on synthetic complete dropout without uracil (SC-uracil) (Sigma) plates supplemented with $20 \mathrm{~g} / \mathrm{L}$ glucose as the carbon source. The ZNF1-overexpressing strain (ZNF1-OE) used in this study (Additional file 2: Table 2) was constructed using the CRISPR/Cas9 gene editing technique. ZNF1 insertion was at chromosome AD7 and, ZNF1 expression was driven by the TEF1 promoter [47]. The yeast culture was regularly maintained in Yeast Peptone Dextrose (YPD) media, containing $10 \mathrm{~g} / \mathrm{L}$ of yeast extract, $20 \mathrm{~g} / \mathrm{L}$ of bacto-peptone, and $20 \mathrm{~g} / \mathrm{L}$ of glucose. Yeast Peptone Xylose (YPX) medium, containing $10 \mathrm{~g} / \mathrm{L}$ of yeast extract, $20 \mathrm{~g} / \mathrm{L}$ of bacto-peptone, and $20 \mathrm{~g} / \mathrm{L}$ of xylose (2\% xylose for YPX) or $100 \mathrm{~g} / \mathrm{L}$ of xylose (10\% xylose for YPX10).

\section{Gene induction and quantitative RT-PCR (RT-qPCR)}

For gene expression analysis during the glucosexylose shift, the $S$. cerevisiae wild-type BY4742, $z$ nf $1 \Delta$, ZNF1-overexpressing (BY4742+ pLJ529-ZNF1), and bud21 + pLJ529-ZNF1 strains were cultured overnight in YPD and then regrown to an approximate $\mathrm{OD}_{600}$ of $0.6-0.8$. Then, they were transferred to YPX and regrown for about $1 \mathrm{~h}$. For gene expression analysis in a low 
glucose-xylose mix, the ZNF1-OE strain was cultured in YPX containing $0.05 \%$ glucose to an approximate $\mathrm{OD}_{600}$ of 4.0. For RNA extraction, RNAs were isolated using the phenol: chloroform: isoamyl alcohol (25:24:1, v/v) method and purified with the RNeasy Mini Kit (Qiagen, Hilden, Germany). The cDNA was synthesised from $2 \mu \mathrm{g}$ of total RNAs according to the qPCRBIO cDNA synthesis kit. RT-qPCR was performed with a CFX Connect Real-Time PCR System (Bio-Rad, CA, USA) and the CFX Connect Real-Time PCR System was used for data analysis. The reaction mixtures contained Luna Universal One-Step RT-qPCR Kit (NEB). The sequences of the primers used for RT-qPCR are listed in Table 4. The relative quantification of each transcript was calculated using the $2^{-\triangle \Delta \mathrm{Ct}}$ method [58] using the $A C T 1$ gene as the internal control. All experiments were performed with at least two independent experiments performed in triplicate.

\section{Xylose fermentation under low glucose-xylose mix conditions}

The ZNF1-OE strain was grown in YPX under low glucose conditions at a concentration of $0.05 \%, 0.04 \%$, $0.03 \%, 0.02 \%, 0.01 \%(\mathrm{w} / \mathrm{v})$, or without glucose to examine its xylose utilising ability. Cells were grown at a temperature of $30{ }^{\circ} \mathrm{C}$ with shaking at $150 \mathrm{rpm}$ for $96 \mathrm{~h}$, and the $\mathrm{OD}_{600}$ of the cell culture was measured using a spectrophotometer and converted into cell biomass. For xylose fermentation, the BY4742+pRS316, BY4742 + pLJ529-ZNF1, bud21 + pRS316, and bud21 + pLJ529-ZNF1 strains were used (Table 4). Cells were cultured in $50 \mathrm{~mL}$ YNB-Ura broth for $16 \mathrm{~h}$, transferred in $250 \mathrm{~mL}$ YPD and incubated overnight at $30{ }^{\circ} \mathrm{C}$ with shaking at $150 \mathrm{rpm}$. The strains containing pRS316 or the pLJ529-ZNF1 plasmid were pre-inoculated in YNB-Ura to maintain the constructs for selection purposes, and the expression level of ZNF1 was checked using RT-qPCR.

Total cells were resuspended in $5 \mathrm{~mL}$ of distilled water and adjusted to an $\mathrm{OD}_{600}$ of 1.0 or cell dry weight (CDW) of $0.23 \mathrm{~g} / \mathrm{L}$ (approximately $0.3 \mathrm{~mL}$ of cell solution) in $50 \mathrm{~mL}$ of YP broth containing xylose at $10 \%$ or $2 \%(\mathrm{w} / \mathrm{v})$ mixed with $0.05 \%(\mathrm{w} / \mathrm{v})$ glucose. Cell samples were harvested daily until 10 or 18 days, respectively, for metabolite analysis via $\mathrm{HPLC}$ and $\mathrm{OD}_{600}$ measurements. The obtained fermentation samples were analysed to determine the concentrations of xylose and glucose, using HPLC (Shimadzu, Japan) with an Aminex HPX$87 \mathrm{H}$ ion-exchange column $(300 \times 7.8 \mathrm{~mm}$ i.d. $)($ Bio-Rad, Hercules, USA). A mobile phase of $5 \mathrm{mM} \mathrm{H}_{2} \mathrm{SO}_{4}$ was used at a flow rate of $0.6 \mathrm{~mL} / \mathrm{min}$ and a column temperature of $65^{\circ} \mathrm{C}$.

\section{Protein extraction and analysis}

BY4742 and $z n f 1 \Delta$ were cultured in $50 \mathrm{~mL}$ of YPD broth, while BY4742+ pLJ529-ZNF1 and bud21 + pLJ529-ZNF1 were cultured in $50 \mathrm{~mL}$ YNB-Ura broth, then transferred to $250 \mathrm{~mL}$ YPD and incubated overnight at $30^{\circ} \mathrm{C}$ with shaking at $150 \mathrm{rpm}$. Total cells were resuspended in $5 \mathrm{~mL}$ of distilled water and adjusted to an $\mathrm{OD}_{600}$ of 1.0 or cell dry weight (CDW) of $0.23 \mathrm{~g} / \mathrm{L}$ (approximately $0.3 \mathrm{~mL}$ of cell solution) in $50 \mathrm{~mL}$ of YP broth containing xylose at $2 \%(\mathrm{w} / \mathrm{v})$ mixed with $0.05 \%(\mathrm{w} / \mathrm{v})$ glucose. Cell samples were harvested for $48 \mathrm{~h}$. Yeast samples were lysed in $0.2 \%$ sodium dodecyl sulphate (SDS) (Amresco, USA), $20 \mathrm{mM}$ dithiothreitol (DTT) (USB, USA), $100 \mathrm{mM} \mathrm{NaCl}$ (Bio Basic, USA), and $50 \mathrm{mM}$ Tris- $\mathrm{HCl}$, pH 8.0 (Bio Basic, USA). Proteins were precipitated using cold acetone solution at a 1:5 ratio $(\mathrm{v} / \mathrm{v})$ and resolubilised using $0.25 \%$ Rapidgest SF (Waters, USA) in $20 \mathrm{mM}$ ammonium bicarbonate (Sigma Aldrich, Denmark). The protein concentrations of the lysates were determined using a BioRad Protein Assay Kit (BioRad, CN). The protein sample in an amount of $25 \mu \mathrm{g}$ was treated with $4 \mathrm{mM}$ DTT at $72{ }^{\circ} \mathrm{C}$ for $30 \mathrm{~min}$ to reduce disulphide bonds, then alkylated using $12 \mathrm{mM}$ iodoacetamide [59] (GE Healthcare, UK) at room temperature in the dark for $30 \mathrm{~min}$ and desalted using a Zeba spin desalting column (Thermo Scientific, Sweden) prior to digestion using trypsin (Thermo Scientific, Lithuania) at a 1:50 protein:trypsin ratio $(\mathrm{w} / \mathrm{w})$ at $37{ }^{\circ} \mathrm{C}$ overnight [60]. The solution was evaporated and reconstituted in 0.1\% FA (Sigma Aldrich, Denmark) in LCMS water (Supelco ${ }^{\circledR}$, Denmark).

A spectral library of yeast for SWATH-MS analysis, $5 \mu \mathrm{g}$ of each digested sample were pooled. Then, $1 \mu \mathrm{g}$ of pooled sample was loaded using nanoLC (Thermo Scientific, Denmark) onto a trap column ( $300 \mu \mathrm{m}$ i.d. $\times 5 \mathrm{~mm}$, packed with 5 m C18 100 Å PepMap ${ }^{\mathrm{TM}}$; Thermo Scientific, Denmark) and desalted with $2 \%$ acetonitrile (ACN) (VWR, France) and $0.05 \%$ trifluoroacetic acid (TFA) (Sigma Aldrich, Denmark) at $10 \mu \mathrm{L} / \mathrm{min}$ for $3 \mathrm{~min}$. Then, the peptides were separated using an analytical column $(75 \mu \mathrm{m}$ i.d. $\times 15 \mathrm{~cm}$, packed d with Acclaim PepMap ${ }^{\text {TM }}$ C18) (Thermo Scientific, Denmark) at $300 \mathrm{~nL} / \mathrm{min}$. The elution was carried out with linear gradient of $3-35 \%$ of buffer B in A for $92 \mathrm{~min}$ (A: $0.1 \%$ FA in water; B: $0.1 \%$ FA in $80 \% \mathrm{ACN}$ ). The eluted peptides were analysed in 6600plus TripleTOF (LC-MS/MS) (ABSCIEX, Denmark). The MS acquisition time was set from gradient time zero to $120 \mathrm{~min}$, and the MS1 spectra were collected in the mass range of 400 to $1,500 \mathrm{~m} / \mathrm{z}$ with $250 \mathrm{~ms}$ in "high sensitivity" mode. Further fragmentation of each MS1 spectrum occurred with a maximum of 30 precursors per cycle. Switch criteria used were the following: charge of $2+$ to $5+, 500 \mathrm{cps}$ intensity threshold and dynamic exclusion for $15 \mathrm{~s}$. 
SWATH-MS data for individual samples were acquired by LC-MS/MS exactly as described above. SWATH acquisition was carried out in data-independent acquisition (DIA) mode. The MS1 spectra were collected in the mass range of 400 to $1,250 \mathrm{~m} / \mathrm{z}$ in "high sensitivity" mode. The variable $\mathrm{Q} 1$ isolation windows were optimised based on the spectral library using the SWATH Acquisition Variable Window Calculator (https://sciex.com/ software-support/software-downloads). Collision energy was different for each window. Single injections of biological triplicates were performed.

The spectral library was processed using ProteinPilot ${ }^{\mathrm{TM}}$ Software 5.0.2 (ABSCIEX, De) with the Saccharomyces cerevisiae database (UniProtKB). The proteins identified by LC-MS/MS in each pooled yeast sample with an unused score above 0.05 (>95\% confidence) and a false discovery rate (FDR) lower than $1 \%$ were considered significant and included in the subsequent analyses. The SWATH-MS data were analysed using PeakView 2.2 software (ABSCIEX, Denmark). The generated spectral library was used as a database for SWATH analysis. Data were processed using an XIC extraction window of $5 \mathrm{~min}$ and XIC width of $75 \mathrm{ppm}$. Peak areas from peptides with $>95 \%$ confidence and $a<1 \%$ global false discovery rate was extracted using MarkerView v1.3.0 (ABSCIEX, Denmark). All annotations were derived from the Saccharomyces Genome Database (SGD) (http://www.yeast genome.org/). Cluster analysis was performed using DAVID bioinformatics resources (https://david.ncifcrf. gov/home.jsp) [61, 62].

\section{Growth and inhibitor tolerance assays}

S. cerevisiae strains were examined for their ability to grow on YPX or YPX-low glucose with or without lignocellulosic inhibitors including FA, LA, and FF. They were grown in YPD broth overnight at $30{ }^{\circ} \mathrm{C}$ with shaking at $150 \mathrm{rpm}$. Yeast cells were harvested and resuspended in distilled water and diluted to an $\mathrm{OD}_{600}$ of $0.1,0.01,0.001$, and 0.0001 . Then, cells were spotted onto YPX agar plates containing $0.05 \%$ glucose or different xylose concentrations, i.e. $2 \%$ or $10 \%(\mathrm{w} / \mathrm{v})$. Cells were grown at $30{ }^{\circ} \mathrm{C}$ for $2-5$ days. Yeast cells were inoculated and cultured at an initial $\mathrm{OD}_{600}$ of 0.1 using 96-well plates, containing $0.2 \mathrm{~mL}$ YPX10 $+0.05 \%$ (w/v) glucose with or without $35 \mathrm{mM} \mathrm{FA}, 85 \mathrm{mM} \mathrm{LA}$, or $20 \mathrm{mM} \mathrm{FF}$. Cells were grown at $30{ }^{\circ} \mathrm{C}$ with shaking $150 \mathrm{rpm}$ for 5 days. The samples were collected at every $24 \mathrm{~h}$ to measure cell density using a Multiskan Sky Microplate spectrophotometer. For the colony forming unit (CFU) count assay, cell samples were diluted and spread onto YPD plates that were incubated at $30{ }^{\circ} \mathrm{C}$ for $48 \mathrm{~h}$.

\section{Xylitol production from rice straw hydrolysate} Rice straw preparation and Xylaria sp. BCC1067 culture

Rice straw was collected from a rice field in Chaiyaphum province, Thailand. Rice straw was dried at $60{ }^{\circ} \mathrm{C}$ for 2 days, then shredded into 5-10 $\mathrm{mm}$ pieces, stored in plastic bags, and kept at room temperature before use. The fungus Xylaria sp. BCC 1067 was obtained from the BIOTEC Culture Collection (BCC culture 6,200,032,292; National Science and Technology Development Agency, Bangkok, Thailand). For inoculum preparation, the Xylaria culture was inoculated on potato dextrose agar (PDA) plates and incubated at $25 \pm 2{ }^{\circ} \mathrm{C}$ for 7 days. The base liquid medium contained $10 \mathrm{~g} / \mathrm{L}$ peptone and $10 \mathrm{~g} / \mathrm{L}$ yeast extract.

\section{Solid-state fermentation}

$10 \mathrm{~g}$ of dried rice straw was placed in a $500 \mathrm{~mL}$ Erlenmeyer flask. Small pieces of agar (plug size $2 \times 2 \mathrm{~mm}$ ) cut from actively growing fungal mycelium were used as the inoculum. The initial moisture content was adjusted to $70 \%$ with the base medium and samples were incubated at $25 \pm 2{ }^{\circ} \mathrm{C}$ for 28 days. For time-course studies, whole flask replicates were collected at designated time points. The sample was extracted with $0.05 \mathrm{M}$ acetate buffer $\mathrm{pH}$ 5.0 by shaking in a rotary shaker at $150 \mathrm{rpm}$ for $2 \mathrm{~h}$ and centrifuged at $8000 \mathrm{rpm}$ for $10 \mathrm{~min}$ at $4{ }^{\circ} \mathrm{C}$. The supernatant was used to determine the enzyme activity.

\section{Cellulase and xylanase activity}

The cellulase activity of the fermented liquid was determined according to [63]. For this, $0.5 \mathrm{~mL}$ of enzyme solution was added to $0.5 \mathrm{~mL}$ of $1 \%$ carboxymethylcellulose $(\mathrm{CMC})$ in $0.05 \mathrm{M}$ citrate buffer ( $\mathrm{pH}$ 5.0). The reaction mixture was incubated at $50^{\circ} \mathrm{C}$ for $10 \mathrm{~min}$. The released reducing sugars were quantified using glucose as a standard. One unit of cellulase (IU) was defined as the amount of enzyme releasing $1 \mu \mathrm{M}$ of glucose per min under the assay conditions. The xylanase activity of the fermented liquid was determined according to a previous publication [64]. Then, $0.5 \mathrm{~mL}$ of enzyme solution was added to $0.5 \mathrm{~mL} 1 \%$ xylan dissolved in $0.05 \mathrm{M}$ citrate buffer ( $\mathrm{pH}$ 5.0). The reaction mixture was incubated at $50{ }^{\circ} \mathrm{C}$ for $10 \mathrm{~min}$. The released reducing sugars were quantified using xylose as the standard. One unit of xylanase was defined as the amount of enzyme releasing $1 \mu \mathrm{M}$ of xylose equivalents per minute under the assay conditions.

\section{Rice straw hydrolysate fermentation}

The BY4742+pRS316, bud21 $\Delta+\mathrm{pRS} 316, \quad$ and bud21 + pLJ529-ZNF1 S. cerevisiae strains were cultured in YPD broth and incubated overnight at $30^{\circ} \mathrm{C}$ with 
shaking at $150 \mathrm{rpm}$. Total cells were resuspended in distilled water and diluted to an $\mathrm{OD}_{600}$ of 1.0, then transferred into $50 \mathrm{~mL}$ of YP broth with liquid rice straw hydrolysate and $0.05 \%$ glucose. Cell samples $(1.5 \mathrm{~mL})$ were harvested until $60 \mathrm{~h}$ for $\mathrm{OD}_{600}$ measurements. The fermentation samples were analysed using HPLC as previously described.

\section{Supplementary Information}

The online version contains supplementary material available at https://doi. org/10.1186/s12934-022-01757-w.

Additional file 1: Gene targets of Znf1 in the central carbon metabolism during growth on the glucose-xylose shift.

Additional file 2: List of plasmids, primers and strains used in this study.

\section{Acknowledgements}

The authors would like to thank Drs. K. Poomputsa (KMUTT, Thailand), C. Tachaapaikoon (KMUTT, Thailand), T. Wongnate (VISTEC, Thailand) and C Auesukaree (Mahidol University, Thailand) for helpful suggestions and W. Samakkarn (KMUTT, Thailand) for technical assistance and fruitful discussion.

\section{Authors' contributions}

Conceptualization, PS and NS; methodology, PS, YY, and NS; formal analysis, $P S, R I, Y Y, C B$, and NS; investigation, PS, RI, YY, CB and NS; resources, $K R$ and NS; writing — original draft preparation, $P S, R I$, and $Y Y$; writing — review and editing, NS; supervision, KR and NS; project administration, NS; funding acquisition, NS. All authors read and approved the final manuscript.

\section{Funding}

This work was supported by research grants from the National Research Council of Thailand, Thailand Science Research and Innovation (TSRI) Basic Research Fund: Fiscal year 2021 under project number 64A306000038 to N.S. King Mongkut's University of Technology Thonburi through the KMUTT 55th Anniversary commemorative fund, the Petchra Pra Jom Klao PhD scholarship, Grant No. 35/2558 supporting P.S.

\section{Author details}

'Division of Biochemical Technology, School of Bioresources and Technology, King Mongkut's University of Technology Thonburi, Bangkok 10150, Thailand. ${ }^{2}$ National Omics Center, National Science and Technology Development Agency, Pathum Thani 12120, Thailand. ${ }^{3}$ Pilot Plant Development and Training Institute, King Mongkut's University of Technology Thonburi, Bangkok 10150, Thailand.

\section{Received: 12 May 2021 Accepted: 14 February 2022}

Published online: 05 March 2022

\section{References}

1. Werpy T, Holladay J, White J: Top value added chemicals from biomass: I Results of screening for potential candidates from sugars and synthesis gas. Pacific Northwest National Laboratory (PNNL) and National Renewable Energy Laboratory (NREL). 2004.

2. Albuquerque TL, da Silva IJ, de Macedo GR, Rocha MVP. Biotechnological production of xylitol from lignocellulosic wastes: A review. Process Biochem. 2014:49:1779-89.

3. Dasgupta Q, Chatterjee K, Madras G. Combinatorial approach to develop tailored biodegradable poly(xylitol dicarboxylate) polyesters. Biomacromol. 2014;15:4302-13.

4. Shankar K, Kulkarni NS, Sajjanshetty R, Jayalakshmi SK, Sreeramulu K. Co-production of xylitol and ethanol by the fermentation of the lignocellulosic hydrolysates of banana and water hyacinth leaves by individual yeast strains. Ind Crops Prod. 2020;155:112809.

5. Mohamad NL, Mustapa Kamal S, Mokhtar M. Xylitol biological production: A review of recent studies. Food Rev Int. 2015;31:74-89.
6. Agbogbo FK, Coward-Kelly G. Cellulosic ethanol production using the naturally occurring xylose-fermenting yeast. Pichia stipitis Biotechnol Lett. 2008:30:1515-24.

7. Sánchez S, Rodríguez V, Castro E, Moya López A, Camacho F. The production of xylitol from D-xylose by fermentation with Hansenula polymorpha. Appl Microbiol Biotechnol. 1998;50:608-11.

8. Wilkins MR, Mueller M, Eichling S, Banat IM. Fermentation of xylose by the thermotolerant yeast strains Kluyveromyces marxianus IMB2, IMB4, and IMB5 under anaerobic conditions. Process Biochem. 2008:43:346-50.

9. Zahoor F, Sooklim C, Songdech P, Duangpakdee O, Soontorngun N. Selection of potential yeast probiotics and a cell factory for xylitol or acid production from honeybee samples. Metabolites. 2021;11:8.

10. López-Linares JC, Romero I, Cara C, Castro E, Mussatto SI. Xylitol production by Debaryomyces hansenii and Candida guilliermondii from rapeseed straw hemicellulosic hydrolysate. Bioresour Technol. 2018;247:736-43.

11. Rocha MVP, Rodrigues THS, de Albuquerque TL, Gonçalves LRB, de Macedo GR. Evaluation of dilute acid pretreatment on cashew apple bagasse for ethanol and xylitol production. Chem Eng J. 2014;243:234-43.

12. Villarreal MLM, Prata AMR, Felipe MGA. Almeida E Silva JB: Detoxification procedures of eucalyptus hemicellulose hydrolysate for xylitol production by Candida guilliermondii. Enzyme Microb Technol. 2006;40:17-24.

13. Dasgupta D, Bandhu S, Adhikari DK, Ghosh D. Challenges and prospects of xylitol production with whole cell bio-catalysis: A review. Microbiol Res. 2017; 197:9-21.

14. Peng B, Shen Y, Li X, Chen X, Hou J, Bao X. Improvement of xylose fermentation in respiratory-deficient xylose-fermenting Saccharomyces cerevisiae. Metab Eng. 2012;14:9-18.

15. Jeffries TW. Engineering yeasts for xylose metabolism. Curr Opin Biotechnol. 2006;17:320-6.

16. Kwak S, Jin YS. Production of fuels and chemicals from xylose by engineered Saccharomyces cerevisiae: a review and perspective. Microb Cell Fact. 2017; 16:82.

17. Zhou H, Cheng JS, Wang BL, Fink GR, Stephanopoulos G. Xylose isomerase overexpression along with engineering of the pentose phosphate pathway and evolutionary engineering enable rapid xylose utilization and ethanol production by Saccharomyces cerevisiae. Metab Eng. 2012;14:611-22.

18. Brat D, Boles E, Wiedemann B. Functional expression of a bacterial xylose isomerase in Saccharomyces cerevisiae. Appl Environ Microbiol. 2009:75:2304-11.

19. Ni H, Laplaza JM, Jeffries TW. Transposon mutagenesis to improve the growth of recombinant Saccharomyces cerevisiae on D-xylose. Appl Environ Microbiol. 2007;73:2061-6.

20. Wenger JW, Schwartz K, Sherlock G. Bulk segregant analysis by highthroughput sequencing reveals a novel xylose utilization gene from Saccharomyces cerevisiae. PLoS Genet. 2010;6:e1000942.

21. Chung Y-S, Kim M-D, Lee W-J, Ryu Y-W, Kim J-H, Seo J-H. Stable expression of xylose reductase gene enhances xylitol production in recombinant Saccharomyces cerevisiae. Enzyme Microb Technol. 2002;30:809-16.

22. Usher J, Balderas-Hernandez V, Quon P, Gold ND, Martin VJ, Mahadevan R, Baetz K: Chemical and Synthetic Genetic Array Analysis Identifies Genes that Suppress Xylose Utilization and Fermentation in Saccharomyces cerevisiae. GBethesda. 2011:1:247-58.

23. Träff KL, Jönsson LJ, Hahn-Hägerdal B. Putative xylose and arabinose reductases in Saccharomyces cerevisiae. Yeast. 2002;19:1233-41.

24. Patiño MA, Ortiz JP, Velásquez M, Stambuk BU. D-xylose consumption by non-recombinant Saccharomyces cerevisiae: A review. Yeast. 2019;89:7.

25. Hou J, Qiu C, Shen Y, Li H, Bao X. Engineering of Saccharomyces cerevisiae for the efficient co-utilization of glucose and xylose. FEMS Yeast Res. 2017:17:23.

26. Tangsombatvichit $P$, Semkiv MV, Sibirny AA, Jensen LT, Ratanakhanokchai $\mathrm{K}$, Soontorngun N. Zinc cluster protein Znf1, a novel transcription factor of non-fermentative metabolism in Saccharomyces cerevisiae. FEMS Yeast Res. 2015:15:2

27. Soontorngun N. Reprogramming of nonfermentative metabolism by stress-responsive transcription factors in the yeast Saccharomyces cerevisiae. Curr Genet. 2017;63:1-7.

28. Songdech P, Ruchala J, Semkiv MV, Jensen LT, Sibirny A, Ratanakhanokchai K, Soontorngun N. Overexpression of transcription factor ZNF1 of glycolysis improves bioethanol productivity under high glucose 
concentration and enhances acetic acid tolerance of Saccharomyces cerevisiae. Biotechnol J. 2020;15:1900492.

29. Wei S, Liu Y, Wu M, Ma T, Bai X, Hou J, Shen Y, Bao X. Disruption of the transcription factors Thi2p and Nrm1p alleviates the post-glucose effect on xylose utilization in Saccharomyces cerevisiae. Biotechnol Biofuels. 2018;11:112.

30. Dzanaeva LS, Ruchala J, Sibirny AA, Dmytruk KV. The impact of transcriptional factors Znf1 and Sip4 on xylose alcoholic fermentation in recombinant strains of yeast Saccharomyces cerevisiae. Cytol Genet. 2020;54:386-92

31. Matsushika A, Goshima T, Hoshino T. Transcription analysis of recombinant industrial and laboratory Saccharomyces cerevisiae strains reveals the molecular basis for fermentation of glucose and xylose. Microb Cell Fact. 2014;13:16.

32. Kuyper M, Harhangi Hr Fau - Stave AK, Stave Ak Fau - Winkler AA, Winkler Aa Fau - Jetten MSM, Jetten Ms Fau - de Laat WTAM, de Laat Wt Fau - den Ridder JJJ, den Ridder Jj Fau - Op den Camp HJM, Op den Camp Hj Fau van Dijken JP, van Dijken Jp Fau - Pronk JT, Pronk JT: High-level functional expression of a fungal xylose isomerase: the key to efficient ethanolic fermentation of xylose by Saccharomyces cerevisiae? 2003

33. Myers KS, Riley NM, MacGilvray ME, Sato TK, McGee M, Heilberger J, Coon $\mathrm{JJ}$, Gasch AP. Rewired cellular signaling coordinates sugar and hypoxic responses for anaerobic xylose fermentation in yeast. PLoS Genet. 2019;15:e1008037.

34. Heinisch JJ, Knuesting J, Scheibe R. Investigation of heterologously expressed glucose-6-phosphate dehydrogenase genes in a yeast zwf deletion. Microorganisms. 2020;8:546.

35. Stincone A, Prigione A, Cramer T, Wamelink MMC, Campbell K, Cheung E, Olin-Sandoval V, Grüning N-M, Krüger A, Tauqeer Alam M, et al. The return of metabolism: biochemistry and physiology of the pentose phosphate pathway. Biol Rev Camb Philos Soc. 2015;90:927-63.

36. Krivoruchko A, Zhang Y, Siewers V, Chen Y, Nielsen J. Microbial acetyl-CoA metabolism and metabolic engineering. Metab Eng. 2015;28:28-42.

37. Elbing K, Larsson C, Bill RM, Albers E, Snoep JL, Boles E, Hohmann S, Gustafsson L. Role of hexose transport in control of glycolytic flux in Saccharomyces cerevisiae. Appl Environ Microbiol. 2004;70:5323-30.

38. Liu G, Li B, Li C, Yuan Y. Enhancement of simultaneous xylose and glucose utilization by regulating $Z W F 1$ and $P G / 1$ in Saccharomyces cerevisiae. Trans Tianjin Univ. 2017;23:201-10.

39. Runquist D, Hahn-Hägerdal B, Bettiga M. Increased expression of the oxidative pentose phosphate pathway and gluconeogenesis in anaerobically growing xylose-utilizing Saccharomyces cerevisiae. Microb Cell Fact. 2009:8:49.

40. Harcus D, Dignard D, Lépine G, Askew C, Raymond M, Whiteway M, Wu C. Comparative xylose metabolism among the Ascomycetes C. albicans, S. stipitis and S. cerevisiae. PLoS ONE. 2013;8:e80733.

41. Matsushika A, Goshima T, Fujii T, Inoue H, Sawayama S, Yano S. Characterization of non-oxidative transaldolase and transketolase enzymes in the pentose phosphate pathway with regard to xylose utilization by recombinant Saccharomyces cerevisiae. Enzyme Microb Technol. 2012;51:16-25.

42. Godon C, Lagniel G, Lee J, Buhler JM, Kieffer S, Perrot M, Boucherie H, Toledano MB, Labarre J. The $\mathrm{H}_{2} \mathrm{O}_{2}$ stimulon in Saccharomyces cerevisiae. J Biol Chem. 1998:273:22480-9.

43. Feng Q, Liu ZL, Weber SA, Li S. Signature pathway expression of xylose utilization in the genetically engineered industrial yeast Saccharomyces cerevisiae. PLOS ONE. 2018;13:e0195633.

44. Cohen R, Yokoi T, Holland JP, Pepper AE, Holland MJ. Transcription of the constitutively expressed yeast enolase gene ENO1 is mediated by positive and negative cis-acting regulatory sequences. Mol Cell Biol. 1987:7:2753-61.

45. Zeng W-Y, Tang Y-Q, Gou M, Xia Z-Y, Kida K. Transcriptomes of a xyloseutilizing industrial flocculating Saccharomyces cerevisiae strain cultured in media containing different sugar sources. AMB Express. 2016;6:51.

46. Bergdahl B, Heer D, Sauer U, Hahn-Hägerdal B, van Niel EW. Dynamic metabolomics differentiates between carbon and energy starvation in recombinant Saccharomyces cerevisiae fermenting xylose. Biotechnol Biofuels. 2012;5:34.

47. Samakkarn W, Ratanakhanokchai K, Soontorngun N. Reprogramming of the Ethanol Stress Response in Saccharomyces cerevisiae by the Transcription Factor Znf1 and Its Effect on the Biosynthesis of Glycerol and Ethanol. Appl Environ Microbiol. 2021;87:e0058821.
48. Zha J, Shen M, Hu M, Song H, Yuan Y. Enhanced expression of genes involved in initial xylose metabolism and the oxidative pentose phosphate pathway in the improved xylose-utilizing Saccharomyces cerevisiae through evolutionary engineering. J Ind Microbiol Biotechnol. 2014;41:27-39.

49. Kwak S, Jo JH, Yun EJ, Jin Y-S, Seo J-H. Production of biofuels and chemicals from xylose using native and engineered yeast strains. Biotechnol Adv. 2019;37:271-83.

50. Hirasawa T, Furusawa C, Shimizu H. Saccharomyces cerevisiae and DNA microarray analyses: what did we learn from it for a better understanding and exploitation of yeast biotechnology? Appl Microbiol Biotechnol. 2010:87:391-400.

51. Risler JK, Kenny AE, Palumbo RJ, Gamache ER, Curcio MJ. Host co-factors of the retrovirus-like transposon Ty1. Mob DNA. 2012;3:12.

52. Costanzo M, Baryshnikova A, Bellay J, Kim Y, Spear ED, Sevier CS, Ding H, Koh JLY, Toufighi K, Mostafavi S, et al. The genetic landscape of a cell. Science (New York, NY). 2010;327:425-31.

53. Osiro KO, Borgström C, Brink DP, Fjölnisdóttir BL, Gorwa-Grauslund MF Exploring the xylose paradox in Saccharomyces cerevisiae through in vivo sugar signalomics of targeted deletants. Microb Cell Fact. 2019;18:88.

54. Baptista SL, Cunha JT, Romaní A, Domingues L. Xylitol production from lignocellulosic whole slurry corn cob by engineered industrial Saccharomyces cerevisiae PE-2. Bioresour Technol. 2018;267:481-91.

55. Delgado Y, Valmaña O, Mandelli D, Carvalho W, Pontes LAM. Xylitol: A Review on the Progress and Challenges of its Production by Chemical Route. Catal Today. 2018;344:234.

56. Jensen LT, Phyu T, Jain A, Kaewwanna C, Jensen AN. Decreased accumulation of superoxide dismutase 2 within mitochondria in the yeast model of Shwachman-Diamond syndrome. J Cell Biochem. 2019;120:13867-80.

57. Gietz RD, Schiestl RH. High-efficiency yeast transformation using the LiAc/SS carrier DNA/PEG method. Nat Protoc. 2007;2:31-4.

58. Livak KJ, Schmittgen TD. Analysis of relative gene expression data using real-time quantitative PCR and the 2(-Delta Delta $C(T))$ Method. Methods. 2001;25:402-8

59. van ZyI W, Lynd L, Den Haan R, McBride J. Consolidated bioprocessing for bioethanol production using Saccharomyces cerevisiae. Adv Biochem Eng Biotechnol. 2007;108:205-35.

60. Krobthong S, Choowongkomon K, Suphakun P, Kuaprasert B, Samutrtai P, Yingchutrakul Y. The anti-oxidative effect of Lingzhi protein hydrolysates on lipopolysaccharide-stimulated A549 cells. Food Biosci. 2021:41:101093.

61. Huang DW, Sherman BT, Lempicki RA. Systematic and integrative analysis of large gene lists using DAVID bioinformatics resources. Nat Protoc. 2009:4:44-57.

62. Huang DW, Sherman BT, Tan Q, Kir J, Liu D, Bryant D, Guo Y, Stephens R, Baseler MW, Lane HC, Lempicki RA. DAVID Bioinformatics Resources: expanded annotation database and novel algorithms to better extract biology from large gene lists. Nucleic Acids Res. 2007;35:W169-75.

63. Mandels M, Weber J: The production of cellulases. In: American Chemical Society; 1969.

64. Warzywoda M, Larbre E, Pourquié J. Production and characterization of cellulolytic enzymes from Trichoderma reesei grown on various carbon sources. Bioresour Technol. 1992;39:125-30.

\section{Publisher's Note}

Springer Nature remains neutral with regard to jurisdictional claims in published maps and institutional affiliations. 